A N N A L E S Annales de Bretagne et des Pays de l'Ouest

\title{
La vie de saint Aubin par Fortunat
}

\section{Élisabeth Carpentier et Georges Pon}

\section{(2) OpenEdition}

\section{Journals}

Édition électronique

URL : http://journals.openedition.org/abpo/3805

DOI : 10.4000/abpo.3805

ISSN : 2108-6443

\section{Éditeur}

Presses universitaires de Rennes

\section{Édition imprimée}

Date de publication : 12 juillet 2018

Pagination : 7-36

ISBN : 978-2-7535-7604-9

ISSN : 0399-0826

Référence électronique

Élisabeth Carpentier et Georges Pon, "La vie de saint Aubin par Fortunat », Annales de Bretagne et des Pays de l'Ouest [En ligne], 125-2 | 2018, mis en ligne le 12 juillet 2020, consulté le 05 janvier 2021. URL : http://journals.openedition.org/abpo/3805; DOI : https://doi.org/10.4000/abpo.3805 


\title{
La vie de saint Aubin par Fortunat
}

\author{
Élisabeth CARPENTIER \\ professeur honoraire à l'université de Poitiers \\ Georges Pon \\ maître de conférences honoraire à l'université de Poitiers
}

Fortunat, le célèbre poète et prosateur italien, installé à Poitiers près de sainte Radegonde, en rédigeant une Vie de saint Aubin, a contribué à créer et amplifier le culte de ce saint. Nous en donnons ici une traduction en français qui contribuera à son tour à réveiller, sinon le culte, du moins le souvenir du saint évêque d'Angers (538-550) ${ }^{1}$. Si l'on excepte la Vita s. Radegundis,

1. à la mémoire d'Yves Chauvin. Commencée par Yves Chauvin et Georges Pon, longtemps abandonnée après le décès du premier qui y travaillait encore dans les derniers mois de son existence, la traduction de la vie de saint Aubin a été reprise par Élisabeth Carpentier et Georges Pon. Le texte a été ensuite soumis à un ami commun, spécialiste reconnu de Fortunat, Marc Reydellet, professeur émérite à l'université de Rennes 2. Ce dernier nous a suggéré de nombreuses corrections que nous avons acceptées avec reconnaissance. Sur la vie du poète italien, voir notamment BRENNAN, B., " The Career of Venantius Fortunatus ", Traditio, 41 (1985), p. 49-78; GEORGE, J.W., Venantius Fortunatus. A Poet in Merovingian Gaul, Oxford, 1992. La production hagiographique de Fortunat a été beaucoup moins étudiée que ses poésies. Son biographe, l'abbé Tardi (Fortunat, étude sur un dernier représentant de la poésie latine dans la Gaule mérovingienne, Paris, 1928), n’y fait que de brèves allusions. À l'exception du Dictionnaire de Spiritualité (AnTIN, Paul, art. "Fortunat ", t. V, 1964, p. 725-726), les grands dictionnaires l'évoquent à peine. L'étude la plus achevée, mais ancienne, est celle de MEYER, W., Der Gelegenheitsdichter Venantius Fortunatus. Abhandlungen der königlichen Gesellschaft der Wessenschaften zu Göttingen, philologisch-historische Klasse, neue Folge, Band 4, NRO 5, Berlin, 1901; voir aussi les pages de BrunHöLzL, F., Histoire de la littérature latine au Moyen Âge, t. I 1, Turnhout, 1990, p. 117-126, notamment p. 125 et les remarques de NAVARRA, L., "Venanzio Fortunato. Stato degli studi et proposte di ricerca ", dans La cultura in Italia tra Tardo Antico et Alto Medioevo. Atti del convegno tenuto a Roma, Consiglia Nazionale delle Ricerche, Rome, 1981, p. 605-610; l'étude plus poussée de PRICoco, S., " Gli scriti agiografici in prosa di Venanzio Fortunato ", Venanzio Fortunato tra Italie e Francia, Trévise, 1993, p. 175-194, et les remarques savantes sur la chronologie des œuvres hagiographiques de Solange QuESNEL (Venance Fortunat, œuvres, t. IV, Vie de saint Martin, texte établi et traduit par S. QuESNEL, Paris, Les Belles Lettres, 1996 [Collection des Universités de France], p. X-XI) ; Boesch Gajano, Sofia, "L'agiografia di Venanzio Fortunato ", Venanzio Fortunato e il suo tempo.Valdobiene, Chiesa di S. Gregorio Magno, 29 novembre 2001, Treviso, Casa dei Carraresi, 30 novembre-1 dicembre 2001, Trevise, 2003, p. 101-116 et surtout ColuINS, 
l'œuvre hagiographique en prose de Fortunat est entièrement constituée de vies épiscopales. Ce sont des œuvres de commande, composées le plus souvent à la demande d'évêques qui voulaient promouvoir le culte de leurs prédécesseurs ${ }^{2}$. Elles s'inscrivent cependant dans un puissant essor du culte des saints évêques aux $\mathrm{V}^{\mathrm{e}}$ et $\mathrm{VI}^{\mathrm{e}}$ siècles $^{3}$ et de la production hagiographique à partir de la fin du $\mathrm{VI}^{\mathrm{e}}$ siècle.

\section{Présentation de la Vita s. Albini de Venance Fortunat}

Si on en croit Bruno Krusch, le dernier éditeur de la Vita sancti Albini ${ }^{4}$ $(B H L, 234)$, la vie de saint Aubin serait la première qu'ait écrite le poète lors de son arrivée en Gaule. Après son pèlerinage à Tours, Fortunat se serait rendu à Angers avant de s'installer à Poitiers et d'y écrire la vie et les miracles d'Hilaire. La longue préface adressée à l'évêque d'Angers Domitianus, mort avant 572, mentionne en effet que c'est au cours d'un voyage de Fortunat à Angers que ce prélat lui a demandé d'écrire la Vie de saint Aubin :

Richard, " Observations on the Form, Language, and Public of the Prose hagiographies of Venantius Fortunatus in the Hagiography of Merovingian Gaul ", dans Columbanus and Merovingian Monasticism, ClARKE, H. B., et alii (dir.) (British Arch. Reports, Intern. Series, 113), Oxford, 1981, p. 105-131, et DEGL'INnOCEnTI, A., " L'opera agiografica di Venanzio Fortunato ", dans Gregorio Magno e l'agiografia tra IV e VII secolo, DeGL'INNOCENTI, A., PRISCO, Antonio de, et PAOLI, Emore (dir.), Florence, 2007, p. 137-153. Nous n'avons pas pu consulter les actes du colloque qui a réuni à Rome les 25-26 janvier 2016 plusieurs spécialistes des œuvres en prose de Fortunat : Écriture italienne, écriture gauloise. Regards croisés sur l'œuvre hagiographique en prose de Venance Fortunat, Rome, École française de Rome.

2. Il s'agit de cinq vies : saint Hilaire (éd. B. KRUSH, mgh aa, IV 2, Hanovre, 1885, p. 1-3 pour la Vita, p. 3-11 pour le Liber de virtutibus sancti Hilarii), de saint Germain de Paris (op. cit., p. 11-27 et éd. B. KRUSH et W. LeVISON, $m g h$, srm, t. vii, Hanovre, MCMXIX, p. 372-422), de saint Marcel (op. cit., p. 49-54), de saint Pair d'Avranches (op. cit., p. 33-37), de sainte Radegonde (éd. KRusch, $m g h$, srm, IV 2, Berlin, 1885, p. 38-49 et mgh, srm, II, Hanovre, 1888, p. 364-377) ; voir aussi CHAUVIN, Yves et Pon, Georges, "Le texte, édition et traduction ", La vie de sainte Radegonde par Fortunat, Poitiers, bibliothèque municipale de Poitiers, manuscrit 250 (136), FAVREAU, Robert (dir.), Poitiers, 1995, p. 55-113; de saint Seurin de Bordeaux (QueNTin, H., "La plus ancienne vie de saint Seurin de Bordeaux », dans Mélanges Léonce Couture, Toulouse, 1902, p. 23-63). Peut-être faut-il aussi rendre à Fortunat la Vita Medardi, si on en croit les recherches de Richard Collins, Observations on the Form, [supra, n. 1]. Sur les autres œuvres attribuées à Fortunat, discussion dans Fiocco, D., « L'immagine des vescovo nelle biografie in prosa di Venanzio Fortunato", dans Venanzio Fortunato e il suo tempo [supra, n. 1], p. 153-169. ici p. 155-156. Dans plusieurs de ces ouvrages, Fortunat mentionne l'identité des ses commanditaires : Vita Hilarii, Vita Martini, Vita Paterni.

3. Brown, Peter, Le culte des saints. Son essor et sa fonction dans la Chrétienté latine, Paris, 1984; BEAUJARD, Brigitte, "Cités, évêques et martyrs en Gaule romaine", dans Les fonctions des saints dans le monde occidental (III $e^{-X I I{ }^{e}}$ siècle). Actes du colloque, Rome, 27-29 octobre 1988, organisé par l'École française de Rome, [Rome] : École française de Rome, 1991, p. 175-191, ici p. 181; Brennan, B. "The image of the Merovingian bishop in Venantius Fortunatus ", Journal of Medieval History, 18, 1992, p. 120-7; PRÉVÔT, Françoise, " évêques gaulois d'origine monastique ", dans Prosopographie et histoire religieuse, actes du colloque tenu à l'université de Paris 7-Val-de-Marne, les 27 et 28 octobre 2000, BASLEZ, M.-F. et PRÉvot F. (dir.), Paris, 2005, p. 394-398.

4. Vita sancti Albini, ed. KRusch, mgh, aa, t. IV 2, Hanovre, 1885, p. 27-33. 
" Je me souviens, homme apostolique, que, me rendant à la ville que vous dirigez pour me présenter à vos regards sous la conduite du Christ, parmi tous les autres mûrs desseins dont je me suis vu submergé par votre intelligence comme par un torrent, vous avez finement suggéré que la vie du très saint Aubin, votre prédécesseur dans l'épiscopat, dont il est prouvé que la vie gravée dans les actes célestes fleurit en mérites qui ne se flétrissent point, soit aussi fixée dans les écrits des hommes et établie pour l'édification du peuple."

La plupart des historiens pensent au contraire que la Vie de saint Aubin est postérieure à la Vie de saint Hilaire. Cette dernière a été composée après l'installation de Fortunat à Poitiers, avant 569, à la demande de l'évêque de la cité Pascentius auquel elle a été dédiée ${ }^{5}$. Et c'est plutôt la qualité de cette œuvre qui a donné l'idée à l'évêque d'Angers Domitianus de faire appel à la plume de Fortunat pour illustrer la mémoire de saint Aubin. On sait par ailleurs par un passage des Carmina que Fortunat avait rencontré l'évêque d'Angers à Tintilliacense ${ }^{6}$, où Domitianus était venu le rejoindre

5. Pascentius, évêque de Poitiers, a succédé à Pientius par la volonté du roi Caribert, roi de Paris, mort à la fin de 567 (Gregorii episcopi Turonensis decem libri, IV, 18, éd. B. KRusch, mgh, srm, I, Hanovre, McmXxxVII, p. 151, l. 15 : Denique cum Pientius episcopus ab hac luce migrasset, apud Parisius civitatem, Pascentius, qui tunc abbas erat basilicae Sancti Hilarii, ei succedit ex jussu regis Chariberti). Il a été remplacé par Marovée vers 568, avant l'arrivée à Poitiers du fragment de la Sainte Croix, selon LABANDE-MAILFERT, Yvonne, Les débuts de Sainte-Croix. Histoire de l'abbaye Sainte-Croix de Poitiers : quatorze siècles de vie monastique, Poitiers, 1985 (Mémoires de la Société des Antiquaires de l'Ouest, $4^{\mathrm{e}}$ sér., 19), p. 38, et Duval, Yves-Marie, "La vie d'Hilaire de Fortunat de Poitiers", dans Venanzio Fortunato e il suo tempo, p. 133-152 [supra, n. 1], ici p. 134 pour la discussion des dates de rédaction des vies de saint Aubin et de saint Hilaire, ce qui permet de resserrer la fourchette chronologique de LAPORTE, DOm J., « Le royaume de Paris dans l'œuvre hagiographique de Fortunat ", dans Études mérovingiennes. Actes des Journées de Poitiers, $1^{\text {er }}-3$ mai 1952, Paris, 1953, p. 169-177, ici p. 175 (entre 565 et 585).

6. Faut-il situer ce monastère en Anjou ou dans le pays d'origine de saint Aubin? La notice de la Bibliotheca sanctorum (I, Rome, 1961, p. 720-721) penche pour Nantilly près de Saumur (Maine-et-Loire), en suivant sans doute l'identification proposée par dom Mabillon (Annales sancti Benedicti, I, p. 80-81) et reprise par CHAMARD, dom François, $L a$ vie des saints personnages de l'Anjou, t. I, Paris, 1863, p. 205. Dom Chamard se fonde sur le voyage que fit Fortunat à Angers en passant par Cariacae et Tincilliacensi : Hinc citus excurrens Cariacae devehor aulae; Tincilliacensi perferor inde loco. Hinc sacer antistes rapuit me Domitianus ad sancti Albini gaudia festa trahens (Carmina, XI, 25, 7-10, éd. REYDELLET, Marc, Venance Fortunat. Poèmes, t. III, Livres ix-xi, Paris, Les Belles-Lettres, 2004 [Collection des universités de France], p. 130). Dom Chamard a lu Carierae qu'il situe à Carrières, près de Thouars, sans fournir un itinéraire suffisamment précis conduisant de Poitiers à Nantilly. Selon Marc Reydellet (n. 73), le terme d'aula pourrait indiquer qu'il s'agit d'une résidence royale, ce qui ne fait guère avancer la solution du problème, comme l'a reconnu Célestin PORT (Dictionnaire historique, géographique et biographique du Maine-et-Loire, t. III, Paris, Angers, 1878, p. 593). La notice des Vies des saints, t. III, Paris, 1941, p. 12 localise le monastère à Tintillant, près d'Angers. Faut-il plutôt penser avec l'article " Aubin " du Dictionnaire d'histoire et de géographie ecclésiastiques (t. 5, Paris, 1931, col. 254) à Théhillac (c. Guer, ar. Vannes, Morbihan). Appelée Treleg en breton, du gaulois Tingillaco (ABALAIN, Hervé, Noms de lieux bretons, 2000, p. 114), cette localité est située sur la Vilaine, dans le pays de Vannes, d'où Aubin était originaire d'après la Vita, à une trentaine de km de Guérande (Loire-Atlantique), où le culte du saint est attesté dans un miracle post mortem (III, 12). Mais cette localisation pose un sérieux problème, car le poème indiquant le passage de Fortunat à Angers pour la fête de saint Aubin le $1^{\text {er }}$ mars est suivi de la description d'un 
pour assister ensuite aux cérémonies solennelles de saint Aubin à Angers ${ }^{7}$. Si l'on en croit la préface, la demande de Domitianus faite à Angers a été relayée ensuite ${ }^{8}$ par l'envoi d'un messager à l'écrivain, chargé de lui fournir des informations sur la Vie de saint Aubin († 450) dont il aurait lui-même pu vérifier l'exactitude. Bien qu'elle soit mentionnée par Grégoire de Tours dans ses Histoires ${ }^{9}$ comme un ouvrage récent, la Vita $s$. Albini a été composée vingt ans plus tôt, avant la mort de Domitianus, auquel elle est dédiée, qu'on date des années 569-572 ${ }^{10}$.

L'œuvre hagiographique en prose de Fortunat a connu un très grand succès au Moyen Âge. C'est pourquoi la Vita sancti Albini est connue par un très grand nombre de manuscrits, comme on peut le voir sur la liste des manuscrits signalés par les Bollandistes sur le site internet Bibliotheca hagiographica manuscripta. Bruno Krusch a cité les principaux ${ }^{11}$. Le texte a été plusieurs fois édité ${ }^{12}$, en dernier lieu dans les Auctores Antiquissimi ${ }^{13}$. Nous nous contentons d'en donner ici une traduction en français ${ }^{14}$.

voyage en bateau sur la Loire, sans doute pour célébrer les fêtes de Pâques avec Félix de Nantes. On imagine difficilement que Fortunat ait pu parcourir successivement à deux reprises l'itinéraire de Théhillac à Angers pour repartir en sens inverse d'Angers à Nantes. Aussi avons-nous laissé dans la traduction le nom latin du monastère.

7. Supra, n. 6.

8. C'est ce qu'indique l'emploi de l'adverbe postmodum au c. 3. Mais on ne sait pas si cette intervention s'est faite " bientôt après " à Angers ou " par la suite " à Poitiers, où Fortunat s'était installé.

9. GREGORIUS TURONENSIS, Liber in gloria confessorum, 94, éd. KRUSCH Bruno, mgh, srm, I, 2, Hanovre, MDCCCLXXV, p. 358 : Albinus autem confessor, cuius nuper vitae liber a Fortunato est conscriptus presbitero, obtenet et ipse, impertiente merito, suum ostendi miracula ad sepulcrum.

10. $m g h$, aa, IV, 2 [supra, n. 4], p. XIII. C'est aussi la fourchette reprise par Venanzio Fortunato, Opere, I, éd. Di Brazzano S., Rome, 2001 (Scrittori della Chiesa di Aquileia, VIII/I), p. 565, n. 31 .

11. mgh, aa, p. XV (BHL 234) : l'édition des Monumenta se fonde principalement sur deux manuscrits : - Codex Vaticanus reginae Christinae, $\mathrm{n}^{\mathrm{o}} 465$, fol. $74^{\mathrm{v}}-81^{\mathrm{v}}$ (cit. PONCELET, Albert, Catalogus codicum hagiographicorum latinorum bibliothecarum Romanarum praeter quam Vaticanae, Bruxelles, 1909 [Subsidia hagiographica, 9], nº 31, p. 322) ; - Paris BnF, lat. 3788, fol. 171-175 (XII ${ }^{\mathrm{e}}$ s.), 5280, fol. 132 (XIII ${ }^{\mathrm{e}}$ s.), 5318, fol. 225-226 (XIII ${ }^{\mathrm{e}}$ s.). Pour plus de renseignements, voir aussi VAN DER STRAETEN, Joseph, Les manuscrits hagiographiques d'Orléans, Tours et Angers, Bruxelles, 1982 (Subsidia hagiographica, 64) et se reporter au site informatique des Bollandistes (Bibliotheca hagiographica latina manuscripta, sous la responsabilité de Xavier Lequeux) qui fournit une liste beaucoup plus complète des manuscrits de la Vita s. Albini.

12. SuRIUS, Laurentius, De probatis sanctorum historiis, Cologne, 1571, II, 1-5 sans indication précise d'origine; MABILlon, Acta sanctorum Sancti Benedicti, Paris, 1668, p. 108-113, d'après Surius; Bollandistes, Acta sanctorum, Mart. I, Anvers, 1668, p. 57-63, d'après des manuscrits de Trêves et Saint-Omer; BouQuet, Recueil des Historiens des Gaules, Paris, 1741, p. 421 sqq. d'après l'édition de Mabillon; Patrologie latine, t. lxxxviii, col. 479 sqq. d'après l'édition de Surius.

13. Éd. Bruno KRUSCH, mgh, aa, t. IV 2 [supra, n. 4], p. 27-33.

14. À notre connaissance, la Vita Albini n'a été traduite qu'en espagnol par BoDELON, Serafin, "Venancio Fortunato. Vida de san Albino ", Magister, Revista de la Escuela Magisteria de Magisterio, t. 19 (2003), Oviedo, p. 201-230. La traduction occupe les pages 219-223. Elle est précédée par une longue présentation de la vie et de l'œuvre de Fortunat qui présente peu d'intérêt pour la compréhension de la Vita. 
La Vie comprend trois grandes parties. L'éloge du dédicataire, écrit dans un latin relevé comme dans les autres prcemia de l'auteur italien, occupe une dizaine de chapitres (c. 1-11), ce qui n'est pas exceptionnel dans les écrits hagiographiques de Fortunat ${ }^{15}$. La deuxième, introduite, comme c'est souvent le cas dans les vies de saints du haut Moyen Âge, par l'adverbe Igitur, encore très proche de l'enkômion antique, raconte la vie du saint depuis sa naissance dans une famille noble du pays de Vannes (c. 11) avec laquelle il rompt très jeune (puerulus) pour entrer au monastère de Tintilliacense (c. 13), la vie ascétique qu'il y mena (13-17), son premier miracle (18-19), son accession à l'abbatiat (21-23) et à l'épiscopat (24-25) ${ }^{16}$. La dernière partie ne traite pas, comme on pourrait le croire, de l'épiscopat d'Aubin - qui est expédié en quelques formules convenues - mais des nombreux miracles accomplis par le saint durant cette période (26-55) : ce sont là les actions qui importent comme dans le discours antique. La mort, à peine évoquée au chapitre 55, est suivie de l'épilogue (55-57), introduit une nouvelle fois par l'adverbe Igitur. Il comporte le récit de la translation des reliques de saint Aubin présidée par saint Germain (55), le récit d'un dernier miracle survenu à cette occasion qui est " le témoignage du bienheureux Aubin vivant après sa mort " (56) et, chose exceptionnelle dans l'œuvre hagiographique de Fortunat, un rappel chronologique de la vie du saint (57).

Comme la Vita Antonii et la Vita Martini et comme les autres ouvres en prose de Fortunat, la structure obéit à un des deux types de récit présents dans l'hagiographie du haut Moyen Âge, soit un enchaînement "d'unités épisodiques (des récits miraculeux notamment), disposées dans un certain ordre chronologique... à la manière des évangiles ${ }^{17}$ ".

15. Le Prologue compte 6 chapitres dans la Vita s. Hilarii (éd. cit. [supra, n. 2] p. 1-2), 7 dans la Vita s. Paterni (op. cit, p. 33-34), 12 dans la Vita s. Marcelli (op. cit., p. 49-50), 4 dans la dédicace à Grégoire de la Vita s. Martini (Opera poetica, Vita s. Martini, éd. F. LEO, mgh, aa, t. IV, Berlin, 1881, p. 293-294).

16. On retrouve là quelques aspects de l'éloge classique (QuinTiLIEN, III, 7, 10 sqq., Institution oratoire Quintilien 2, Livres III et IV, texte établi et traduit par Cousin, Jean, Paris, Les Belles Lettres, 1976, p. 191 sqq.) : la patrie d'origine, la famille, l'éducation (qui se fait ici dans le monastère). Naturellement il n'est pas question ici de l'aspect physique du saint : un saint n'a pas de corps (voir PERNOT, Laurent, La rhétorique dans l'Antiquité, Paris, 2000, p. 293-294).

17. VAn UytFanghe, Marc, "L'hagiographie en Occident de la Vita Antonii aux Dialogues de Grégoire le Grand, genèse et occupation du terrain ", dans Gregorio Magno e l'agiografia tra IV e VII secolo [supra, n. 1], p. 3-52, ici, p. 21. Ces " unités épisodiques " sont plus ou moins bien liées par des adverbes de temps : mox (c. 13), denique (c. 14), deinde (c. 30), tunc (c. 34, 37, 42, 48), iterum (c. 43), interea (c. 57), par des ablatifs absolus : quo facto (c. 27,53) ou, plus rarement, par des adverbes d'affirmation ou de cause : enim (c. 15, 16), vero (c. 39), nam (c. 56). Comme l'a relevé Richard Collins dans un mémoire soutenu à la Sorbonne en 1977 (Rhetorica et sermo rusticus en Gaule romaine) et résumé dans Observations on the Form [supra, n. 1], p. 109-110, igitur et unde perdent parfois leur force logique et deviennent de simples " particules de transition ". Igitur est utilisé dans un sens classique pour aborder un développement annoncé précédemment, à savoir le début du récit de la Vita (c. 11). 
On vient de signaler que le dernier chapitre de la Vita apportait des précisions chronologiques intéressantes ${ }^{18}$ : Aubin est mort dans " dans la quatre-vingtième année de sa vie ", le $1^{\mathrm{er}}$ mars 550 . Il avait gouverné le diocèse d'Angers pendant vingt ans et six mois. Les chapitres 21 et 23 nous avaient déjà appris qu'il avait été élu abbé vers l'âge de 35 ans et avait dirigé la communauté monastique de Tintilliacense 25 ans. Peut-être ces repères chronologiques ont-ils été fournis à Fortunat lors de séjours qu'il a faits à Tintilliacense et à Angers ${ }^{19}$. Peut-être les a-t-il aussi recueillis de la bouche de l'informateur que lui avait spécialement envoyé l'évêque Domitien. Fortunat dit le plus grand bien de la véracité des informations qui lui ont été communiquées par cet individu et qu'il aurait contrôlées par d'autres témoignages (c. 4$)^{20}$, mais il doit bien reconnaître que beaucoup d'actions du saint sont demeurées cachées ou ont disparu de la mémoire du narrateur. À vrai dire, même si saint Aubin est mort que depuis une vingtaine d'années, comme la plupart des saints dont Fortunat a rapporté les actes ${ }^{21}$, il en sait davantage sur saint Aubin qu'il n'en savait sur saint Hilaire. Il a consulté un témoin de confiance et fait une contre-enquête ${ }^{22}$, ce qui lui a permis de rassembler quelques éléments biographiques plus ou moins vérifiables. Mais cet hagiographe n'est pas un biographe. Aussi le discours est-il assez convenu et se structure-t-il sur la dualité : vie monastico-ascétique débouchant sur la puissance thaumaturgique qui conditionne l'accès à l'épiscopat ${ }^{23}$.

18. Au c. 50 de la Vita s. Marcelli, Fortunat se borne à mentionner la mort du saint die Kalendarum Novembrium.

19. Peut-être a-t-il pu relever une partie de ces renseignements sur une inscription funéraire.

20. Cette curiosité de caractère historique est assez exceptionnelle chez Fortunat qui ne s'intéresse guère à l'histoire et encore moins à la critique historique mais conçoit l'œuvre hagiographique comme l'actualisation des vertus thaumaturgiques du saint en vue de l'édification du peuple (BoEsch GAJANO, Sofia, "L'agiografia di Venanzio Fortunato ", Venanzio Fortunato e il suo tempo [supra, n. 1]. p. 101-116, ici p. 110).

21. Saint Pair, évêque d'Avranches, est mort à la fin des années 560 et Germain, évêque de Paris, en mai 576.

22. La vérification des sources par l'appel à des témoins véridiques et par une enquête personnelle est fréquente dans les œuvres hagiographiques de l'Antiquité tardive, FAUQUIER, Michel, La sainteté à la fin de l'Antiquité et au début du Moyen Âge d'après les vitæ sancti gauloises, thèse soutenue à l'université de Nantes le 29 mai 2016, dactyl., p. 32-33. Peut-être cet auteur se fait-il quelque illusion sur les qualités d'historien des hagiographes. Mais, sur les événements qui sont aujourd'hui vérifiables comme la participation de saint Aubin au concile d'Orléans de 538, elle est attestée par les actes concilaires, infra, n. 40. Quant à savoir s'il s'est effectivement rendu à Paris pour rencontrer le roi Childebert, ce n'est pas impossible.

23. Cette structure s'inspire clairement de l'exemple de Martin, ascète et moine à Ligugé avant de devenir évêque de Tours (FonTAINE, Jacques, "Biographie et politique, de Sulpice Sévère à Venance Fortunat ", La christianisation des pays entre Loire et Rhin (IV ${ }^{e}$ VII siècles), Revue d'histoire de l'Église de France, t. Ixii, no 168, 1975, p. 113-140, ici p. 116 et 126 : "Fortunat a choisi et présenté un certain nombre d'épisodes de sa biographie ascétique selon les catégories d'une "imitation de saint Martin". " Mais il est possible qu'il ait suivi aussi d'autres modèles : la vie de saint Ambroise par Paulin de Milan ou celle d'Hilaire d'Arles, attribuée à Honorat de Marseille (voir VAN UYTFANGHE, L'hagiographie en Occident 
L'auteur n'insiste guère sur les origines d'Aubin. Il relève cependant au début de la Vita proprement dite (c. 11) qu' « originaire du pays des Vénètes aux confins de l'Océan britannique ${ }^{24}$, il naquit de parents qui n'étaient pas de modeste extraction mais plutôt issus d'une très noble race : l'honneur qu'il reçut de sa noble ascendance, il l'augmenta par les mérites de sa vie bienheureuse ». Un peu plus loin, il précise qu'il était " de bonne famille..." (c. 13). Ces notations sont difficiles à interpréter. La mention de la " naissance libre " au c. 13 pourrait faire penser à une famille noble et puissante politiquement ${ }^{25}$, même si Fortunat, à la différence de Grégoire de Tours, ne cherche pas à rattacher saint Aubin à une lignée sénatoriale. L'éloge qu'il fait de sa lignée n'a pas l'éclat du panégyrique de Félix de Nantes dans les Carmina $^{26}$, mais c'est le même terme - genus - qui est utilisé dans les deux cas puisque Félix est qualifié de lumen generis, "lumière de la noblesse ". Ce thème de la naissance noble, devenu par la suite un topos, est une innovation de Fortunat. " Il est le premier d'une longue succession d'hagiographes à faire de la noblesse la véritable fondation d'une carrière épiscopale ${ }^{27}$ ". Mais est-il bien nécessaire d'insister sur le topos bien connu de la naissance noble, prolongé au chapitre suivant par la vocation précoce qui entraîne la rupture avec les parents, conforme aux enseignements de Jésus ${ }^{28}$ et aux

[supra, n. 17], p. 20; voir aussi MoReIRA, Isabel, Dreams, Visions and Spiritual Authority in Merovingian Gaul, Cornell University, Ithaca et Londres, 2000, p. 50-51).

24. Plus tard la tradition le fera naître à Guérande : "Le lieu de naissance du saint évêque n'est pas privé de la munificence de ses vertus. En effet, dans le pays de Vannes (ou des Vénètes), il existe une bourgade située au bord de l'Océan que la langue bretonne appelle Guérande, assez peuplée en raison d'un important commerce du sel. " (voir l'article sur le culte de saint Aubin. Miracles par un moine d'Angers, III).

25. La noblesse est souvent associée depuis l'époque romaine à la liberté (MARTIN, JeanPierre, "Res publica, libertas et principat ", dans Auctoritas. Mélanges offerts au professeur Olivier Guillot, Paris, 2006, p. 35-44, ici p. 36. On trouve des expressions semblables à celles de Fortunat dans un passage de Grégoire de Tours concernant Aredius, un habitant de Limoges, non mediocribus regionis suae ortus parentibus, sed valde ingenuis (Gregorii episcopi Turonensis Historiarum, X, 29, éd. KRUSCH [supra, n. 5], p. 522). Cependant, dans la Vie de saint Patrocle, saint d'origine modeste, Grégoire de Tours distingue la noblesse de la liberté, lorsqu'il écrit que Patrocle et son frère étaient non enim nobilitate sublimes, ingenui tamen (Vitae Patrum, IX, 1, éd. Krusch, mgh, srm, I, II, p. 1). Dans la Vita s. Paterni, il est dit que saint Pair était issu de bonis parentibus, c. 30, éd. cit. [supra, n. 2] p. 35.

26. Carmina, III, 5, 5, éd. Reydellet, Venance Fortunat, Poèmes, t. I, Livres I-IV [supra, n. 6], p. 91 et BüHRER-THIERRY, Geneviève, «Entre panégyrique antique et théologie de la lumière. L'éloge des évêques selon Venance Fortunat ", Auctoritas. Mélanges... [supra, n. 25], p. 147-156, ici p. 149.

27. Coluins, Observations on the Form, [supra, n. 1], p. 114 et 127. Cet auteur considère même que Fortunat se fait ainsi l'interprète de la noblesse gallo-romaine jalouse de conserver les charges épiscopales. Voir HEINZELMANN, Martin, Bischofsherrschaft in Gallien. Zur Kontinuität römischer Führungeschichte vom 4. bis zum 7. Jahrundert. Soziale, prosopographische und bildungsgeschitliche Aspekte, Munich, 1976 (Beihefte der Francia, 5), et LE JAN, Régine, La société du haut Moyen Âge, Paris, 2003. p. 157-160 et 173.

28. Mt 10, 37 : "Celui qui aime son père ou sa mère plus que moi n'est pas digne de moi. "Sur les clichés obligés dans les œuvres en prose de Fortunat, voir Consolino, F. E., Ascesi e mondanità nella Gallia tardoantica. Studi sulla figura del vescovo nei secoli IVVI, Naples, 1979, p. 83-84 et BoEsch GAJANO, "L'agiografia di Venanzio Fortunato », dans Venanzio Fortunato e il suo tempo [supra, n. 1], p. 101-116, ici p. 109-110. 
modèles hagiographiques, puisqu'elle est une rupture avec le monde et la première manifestation du contemptus mundi ${ }^{29}$.

La suite obéit également à un modèle hagiographique connu où la vie ascétique et monastique est une étape indispensable pour acquérir la vertu d'un saint et ses pouvoirs thaumaturgiques avant l'exercice des responsabilités épiscopales. C'est aussi le cas, on le sait, de saint Martin, de saint Honorat $^{30}$ et des saints Pair et Germain ${ }^{31}$.

La narratio ou plus exactement la justificatio, en effet, évoque assez longuement l'entrée au monastère de Tintilliacense et les vertus qu'Aubin y déploie : humilité, obéissance absolue (c. 13), la pratique de l' " exercice quotidien ", entendons l'office (c. 14), les jeûnes, la prière, l'œuvre de "compassion " (miserationis) (c. 16), la "gravité ", vertu romaine devenue vertu monastique, car elle exclut du cloître la légèreté et les plaisanteries (c. 17). Il n'est pas question d'études et cette formation ascétique ne trouve son sens que dans une relation intime au Christ : " n'ayant rien de commun avec l'homme que le fait d'être né, il voulut pour tout le reste n'appartenir qu'au Christ " (c. 16). Belle formule qui est reprise sous une autre forme au chapitre suivant : " il resta toujours enfermé dans la prison de son cœur et n'offrit à regarder en dehors de lui que le Christ qu'il portait fidèlement dans son cœur ${ }^{32}$ ". Et c'est bien cette proximité avec le Christ plus encore que les pratiques ascétiques qui lui permet de faire son premier miracle (c. 18-19), de manifester publiquement sa sainteté (c. 20) et d'accéder à l'abbatiat (c. 21).

Celui-ci aurait duré 25 ans (c. 23) mais le récit qui en est fait n'occupe que trois courts chapitres peu documentés. Ils ont seulement pour fonction d'expliquer par l'immense renommée de l'abbé l'élection à Angers d'Aubin par le consentement universel des Angevins, autre topos de l'hagiographie épiscopale, qui rompt avec les difficultés qu'aurait connues Martin dans son accession au siège de Tours ${ }^{33}$.

29. FAUQUIER, Michel, La sainteté..., [supra, n. 22], p. 48 note l'importance du De contemptu mundi d'Eucher de Lyon (370-449) ; voir aussi p. 123, 127-131. Sur la rupture avec les parents aristocrates, voir les deux premiers chapitres de la Vita s. Germani, éd. B. KRUSCH, mgh, srm, VII [supra, n. 2], p. 373.

30. Saint Honorat, fondateur et abbé de Lérins (vers 410) puis évêque d'Arles († 430).

31. Saint Germain a été abbé de Saint-Symphorien d'Autun avant de devenir évêque de Paris. Fortunat s'inspire aussi bien de la Vita Martini que de l'hagiographie lérinienne. Voir FIocco, "L'immagine del vescovo nelle biografie in prosa di Venanzio Fortunato " [supra, n. 2], p. 153-169 et Collins, Observations on the Form [supra, n. 1], p. 111, Degl'INNOCENTI, "L'opera agiografica di Venanzio Fortunato " [supra, n. 1], p. 140; VAN UYTFANGHE, "L'hagiographie en Occident " [supra,n. 17], p. 33-34.

32. On a là comme une définition de la conversatio qui consiste à se tourner vers le Christ pour une conversion sérieuse. Voir VoGUË, Adalbert de, La règle de saint Benoît, passim, en particulier t. VII, Paris, 1977 : Commentaire doctrinal et spirituel, p. 69.

33. Vita Martini, Iv, 1, éd. / trad. FonTAINE, Jacques, Vie de saint Martin, I, Paris, 1967 (Sources chrétiennes, n ${ }^{\circ}$ 133), p. 271-272. Dans la réécriture en vers de la Vita Martini, Fortunat, comme l'a relevé Michel Fauquier, atténue ces contestations scandaleuses (Vie de saint Martin, éd. et trad. par S. Quesnel, [supra, n. 1], p. 15). 
La dernière partie, de loin la plus longue (c. 24-54), concerne l'épiscopat d'Aubin, la vie publique, la vie active après le temps de l'ascèse et de la contemplation. À vrai dire, c'est plus le thaumaturge que l'évêque qui occupe le devant de la scène. Le prélat apparaît seulement au début et à la fin. Le texte énumère quelques aspects de la " charge sacerdotale " telle qu'on la concevait au $\mathrm{VI}^{\mathrm{e}}$ siècle : le soin des pauvres, la visite des malades, la libération des captifs, la " défense des citoyens ". Aubin est ainsi présenté comme le "défenseur de la cité " (defensor civitatis) ${ }^{34}$, capable d'imposer son autorité aux autres pouvoirs en libérant une captive de haut rang (c. 33-34) ${ }^{35}$ et de simples prisonniers enfermés dans une tour de l'enceinte d'Angers (c. 44-45). La présence épiscopale ne se limite pas à la cité : l'évêque ne cesse de se déplacer, si on en croit les prodiges qu'il a accomplis en divers lieux, bourgades ou monastères du diocèse d'Angers et des diocèses voisins ${ }^{36}$. La sainteté d'Aubin est une sainteté active comme celle de saint Pair ou de saint Germain ${ }^{37}$. Suivant un topos fréquent dans l'hagiographie du haut Moyen Âge, le saint évêque veut se rendre auprès du roi, mais ce voyage n'est pas un signe de soumission au pouvoir royal, car le roi lui-même, voulant aller à sa rencontre, ne peut le rejoindre qu'après avoir consenti à se détourner de la route qu'il avait choisie pour suivre la bonne voie (c. 38-40). Mais Fortunat, avec la subtilité diplomatique qu'on lui connaît, ne cherche ni à noircir l'image du roi ni à l'humilier comme le font Sulpice Sévère dans la Vita Martini et les Dialogi ou Paulin de Périgueux dans sa Vita Martini ${ }^{38}$.

34. L'expression defensor civitatis n'est pas utilisée par Fortunat ni celle de patronus. Saint Seurin a été envoyé à Bordeaux ad salvandum populum, " pour sauver le peuple " (Quentin, La plus ancienne vie de saint Seurin de Bordeaux [supra, n. 2], p. 23-63, ici, c. 1-2, p. 60-63). Sur les origines du rôle de l'évêque dans les cités, voir les pages lumineuses de Brown, Peter, Pouvoir et persuasion dans l'Antiquité tardive, Paris, 1998, p. 167 sqq. Sur le patronage des évêques, voir BEAUJARD, Cités, évêques et martyrs en Gaule romaine [supra, n. 3], ici p. 178-179, ISAÏA, Marie-Céline, "Le saint évêque dans l'hagiographie lyonnaise (IV ${ }^{\mathrm{e}}-\mathrm{VII}^{\mathrm{e}}$ siècle) ", L'empreinte chrétienne en Gaule du IV au IX siècle, Études réunies par GAILLARD, Michèle, p. 111-129, sans oublier les vues de WERNER, Karl-Ferdinand, exposées notamment dans " La place du VII ${ }^{\mathrm{e}}$ siècle dans l'évolution politique et institutionnelle de la Gaule franque ", Le septième siècle. Changements et continuité / The Seventh Century. Change and Continuity, éd. Fontaine, J. et HILlGaRTH, N., Londres, 1992, p. 173-211, notamment p. $178 s q q$; voir en dernier lieu MAZEL, Florent, L'évêque et le diocèse, l'invention médiévale de l'espace, Paris, 2016, p. 43-73. Plus spécialement pour l'œuvre de Fortunat, voir les remarques d'OrSELl, A. M., "In santo patrono cittadino : genesi et sviluppo del patrocinio dei vescovi nei secoli VI e VII ", Agiografia altomediovale [supra, n. 1], p. 86-88 et Fiocco, D., "L'immagine del vescovo nelle biografie in prosa di Venanzio Fortunato " [supra, n. 3], p. 160.

35. Sur le rachat des captifs, voir aussi DEGL'INNOCENTI, « L'opera agiografica di Venanzio Fortunato " [supra, n. 1], p. 149.

36. Il se rend dans la cité de Vannes (c. 41).

37. Vita Paterni, c. 16, éd. cit. [supra, n. 15], p. 37. L'origine de cette "sainteté active " serait à chercher dans la vie de saint Germain d'Auxerre (CONSTANCE DE LYON, Vita Germani episcopi Autissiodorensis, éd. René Borius, Paris, 1965 [Sources chrétiennes, 112]) selon VAN UYTFANGHE, "L'hagiographie en Occident " [supra,n. 17], p. 35.

38. Voir FonTAINE, " Hagiographie et politique " [supra, n. 23], p. 118-122. 
Aux chapitres 55-57, Fortunat mentionne, ce qui est assez rare ${ }^{39}$, la participation de saint Aubin aux synodes. Il n'en donne pas le nom mais on peut facilement identifier l'un d'entre eux, le concile d'Orléans V de 538 auquel assistait bien l'évêque d'Angers : "Albinus, au nom du Christ évêque de l'église d'Angers, j'ai consenti ${ }^{40}$ ". La Vita explique qu'il fut contraint par les autres évêques d'absoudre des personnes qui avaient été excommuniées. La Vita indique au c. 49 qu'il condamnait " selon le droit (jure) les copulations exécrables des noces incestueuses ${ }^{41}$ ", comme l'avaient fait les canons 18 du concile d'Orléans de $511^{42}$ et 30 du concile d'Épaon du 15 septembre $517^{43}$. Ces dispositions furent reprises au canon 11 du concile d'Orléans en $538^{44}$. Sans doute l'excommunication a-t-elle été exceptionnellement levée par les pères conciliaires en faveur d'une personne non identifiée. Saint Aubin, plus intransigeant que les Pères, fut contraint par les autres évêques d'absoudre des personnes qu'il avait excommuniées et même "d'apposer aussi lui-même le signe de la croix sur les eulogies que les autres évêques avaient bénies pour les envoyer à une personne excommuniée" (c. 52). Mais, comme un prophète vétéro-testamentaire, il en appelle directement à la vengeance divine qui va se produire au chapitre 53, non sans en avoir référé, prétend Fortunat, à Césaire d'Arles.

Césaire, évêque d'Arles pendant quarante ans (v. 500-543), jouissait d'un grand prestige dans l'église de Gaule. Nommé vicaire du Siège apostolique pour la Gaule et l'Espagne et doté du pallium par le pape Symmaque ${ }^{45}$, il avait convoqué et présidé plusieurs conciles, Agde en 506, Arles en 524, Carpentras en 527, Orange II en 529 qui influencèrent les assemblées réunies dans la Gaule septentrionale. Mais aucun de ces conciles, à notre connaissance, n'a légiféré sur les relations incestueuses et leurs excommunications ${ }^{46}$. Il n'est pas impossible que la référence à Césaire ait été

39. FAUQUIER, La sainteté à la fin de l'Antiquité [supra, n. 22], p. 381 et 673 : «Les Vitae, en contradiction avec les faits, donnent l'impression que les saints évêques ne se sont pour ainsi dire jamais rendus à des conciles. En fait, les hagiographes ne veulent pas impliquer les saints dans le règlement d'affaires trop ordinaires. "

40. Voir Les canons des conciles mérovingiens $V I^{e}-V t^{e}$ siècles, t. I, par GAUDEMET, Jean et Basdevant, Brigitte, Paris, éd. du Cerf, 1989, p. 261. Aubin était aussi présent au concile d'Orléans IV de 541 ("Albinus, au nom du Christ, évêque de la cité d'Angers, j'ai souscrit ", op. cit., p. 293), mais il s'est fait représenter par l'abbé Sapaudus au concile d'Orléans de 549 (op. cit., p. 327) : "Sapaudus, abbé délégué par mon seigneur Albinus, évêque de l'église d'Angers, j'ai souscrit. »

41. Ces interdictions trouvent peut-être leur source dans la parole de Jean-Baptiste à Hérode ("Il ne t'est pas permis de l'avoir [Hérodiade] " Mt. 14, 3),

42. Les canons des conciles mérovingiens [supra, n. 40], I, p. 114-116.

43. Op. cit., I, p. 114-117.

44. "Que personne ne se permette de s'unir par un prétendu mariage à la veuve de son frère, à la sœur de sa femme, à sa cousine germaine ou issue de germaine, à la veuve de son oncle paternel ou maternel... " La formulation semble indiquer que les Pères maintenaient le caractère non rétroactif décidé au synode précédent pour la période d'avant 538.

45. CÉSAIRE D’ARLES, Sermons au peuple, t. I, Sermons 1 à 20, Introduction, traduction et notes par Delage, Marie-José, Paris, 1971 (Sources chrétiennes, nº 175), p. 42.

46. Césaire critique assez souvent les vices des citoyens d'Arles mais il n'a pas, semblet-il, critiqué les "noces incestueuses ", v. Opera [Caesarii Arelatensis], t. II : Sancti Hilarii 
inventée par Fortunat en raison du prestige de l'évêque d'Arles en Gaule et plus spécialement à Poitiers dans l'entourage de Radegonde ${ }^{47}$. Peut-être voulait-il suggérer qu'il existait une sorte de réseau de sainteté entre l'Ouest et le Sud-Est de la Gaule ${ }^{48}$.

L'épiscopat n'est pas seulement l'aboutissement d'une vie d'ascèse dans un monastère. Même s'il n'a que peu de contact avec la vie cénobitique $^{49}$, l'ascèse reste au cœur de l'évêque ${ }^{50}$, puisqu'au chapitre 50 , il est écrit qu'il " aurait souhaité devenir martyr ". Ce thème du martyre souhaité est fréquent chez Fortunat, qui s'inspire de la Vita Martini ${ }^{51}$ dans ses œuvres en prose, dans la vie de saint Germain ${ }^{52}$, dans celle de saint Pair ${ }^{53}$ ainsi que dans la Vita Radegundis, où il met l'accent sur le désir de martyre de Radegonde. Il montre la sainte reine martyrisant son corps par d'horribles supplices qui font frémir le lecteur comme ils ont fait frémir l'auteur, ami et confident de la sainte, dans les chapitres 25 et 26 de la Vita. Alors que dans la Vita Radegundis, les supplices que la sainte reine s'inflige vont jusqu'à " l'effusion de sang ", il s'agit le plus souvent d'un martyrium sine cruore, d'un "martyre sans effusion de sang " sur le modèle martinien de Sulpice Sévère ${ }^{54}$. Dans la Vie de saint Aubin, il est

Caesarii Arelatensis Sermones, Turnhout, Brepols, 1953 (Corpus christianorum, series latina, 104) et CÉSAIRE D’ARLES, Sermons au peuple, I, p. 131-134. La Vita Caesarii, comme l'a remarqué Michel FAUQUIER (La sainteté à la fin de l'Antiquité [supra, n. 22], p. 419-420), ne fait qu'une seule allusion (I, 60) à l'activité conciliaire de Césaire.

47. Césaire d'Arles est souvent mentionné dans les Carmina, v, 2, 68; 3, 40;3, 41; 3, $48 ; 3,82 ; 3,158$; voir notamment $a p p$. XIII, 1 : "Que la gloire de Césaire vous arme de son enseignement en ce monde et que le Christ avec son Père bien-aimé vous chérisse toutes deux... " Sur les relations de sainte Radegonde avec Arles, voir LABANDE-MAILFERT, "Les débuts de Sainte-Croix " [supra, n. 5], p. 42 sqq.

48. Sur ces réseaux de sainteté dans l'espace gaulois, voir l'article encore inédit de Michel FAUQUIER, "Les réseaux des saints d'après les Vitce sanctorum gauloises : une autre vision de l'espace." "

49. Sur ce point, Fortunat s'écarte de Martin qui, même après son accession à l'épiscopat, continue à vivre comme un moine à Marmoutier (SUlPICE SÉvèRE, Vita Martini, IV, 2, VIII, 1-2 éd. / trad. FonTAINE, Vie de saint Martin, I [supra, n. 33], p. 272-275, 309-311). Aubin, au contraire, se borne à visiter son ancien monastère de Tintilliacense (c. 43) et celui d'Asiagus.

50. De même, saint Germain reste-t-il moine après avoir accédé à l'épiscopat (CONSTANCE DE LYON, Vie de saint Germain d'Auxerre, c. 2-6, éd. BoRIUs [supra, n. 37], p. 125-131).

51. Sulpice SÉvère, Vita Martini, x, 2, éd. Fontaine, Vie de saint Martin, I [supra, n. 33], p. 328-329 (et commentaire, t. I, p. 152; t. II, p. 537; t. III, p. 1166, 1216 sqq.) : Il a rejoint le troupeau des martyrs " et, tout immaculé, il fait cortège à l'agneau qui les guide. Car les circonstances actuelles ont beau n'avoir pu lui assurer le martyre, il n'en sera point pour autant dépourvu de la gloire du martyr, car, par son désir et sa valeur, il aurait pu aussi bien que voulu être martyr. "

52. Vita Germani, c. LXXV, éd. cit. [supra, n. 2], p. 416-417 : Il pratiquait une pénitence telle que domestico tormento superato corpore, de se triumphatum in pace factus martyr adquireret (p. 417).

53. Vita Paterni, éd. cit. [supra, n. 15], p. 34.

54. La Vita sancti Martini de Sulpice-Sévère au début du ve siècle fait l'éloge du " martyre non sanglant "-martyrium sine cruore. Comme l'a relevé Jacques Fontaine (Vie de saint Martin [supra, n. 33], t. III, p. 1232), l'expression est apparue pour la première fois sous la 
question de la main d'un assassin : « il aurait souhaité devenir martyr; il ne lui manqua que la droite de l'assassin, mais, sans aucun doute, il mérita la palme du martyre, lui qui ne se cacha pas d'avoir formulé ce vœu ". On voit ainsi que, tout au long de son ouvre, Fortunat aime à faire revivre sous des formes diverses ce souhait de martyre qui permet après la fin des persécutions de rapprocher le confesseur du martyr dans l'imitation des souffrances du Christ ${ }^{55}$.

Car c'est en imitant le Christ que le saint a pu accumuler l'énergie, la puissance surnaturelle, en un mot la " vertu " qui va lui permettre de faire des miracles. Aussi le thaumaturge tient-il ici plus de place que l'abbé et l'évêque.

Alors que Fortunat avait séparé la Vie de saint Hilaire de ses miracles, il réunit ici dans la même œuvre la vie et les miracles, comme il l'a fait aussi dans les autres vies en prose de saint Germain, de saint Marcel et de saint Pair. On compte une quinzaine de miracles qui occupent une trentaine de chapitres, soit plus de la moitié du total. Le miracle est bien l'élément dominant de la $\mathrm{Vita}^{56}$, le révélateur, la manifestation de la sainteté ${ }^{57}$, ou, plus exactement, à travers le saint, " la manifestation sur terre du pouvoir de Dieu ${ }^{58}$ ». Un seul miracle remonte à la période monastique ${ }^{59}$. Encore faut-il noter que ce premier prodige rapporté aux c. 18-20, même s'il est spectaculaire puisque seul Aubin échappe à une averse dévastatrice, n'est pas un miracle aussi sérieux que ceux qui se produisent après l'accession à l'épiscopat. C'est notamment le cas d'un jeune homme ramené à la vie au chapitre 28. Ce miracle n'est pas spécialement mis en valeur dans l'énumération des prodiges. Les contemporains reconnaissaient immédiatement un prodige martinien ${ }^{60}$ qui avait déjà inspiré Fortunat dans la

plume de Paulin de Nole, ami de Sulpice Sévère, à propos de l'illustre confesseur Félix, Carmina, 121 et 9 : Inclite confessor, meritis et nomine Felix, [...] uectus in aetherium sine sanguine martyr honorem...

55. Sur l'imitation ou la nostalgie du martyre, voir HeInZELMANN, Martin, " Pouvoir et idéologie dans l'hagiographie mérovingienne ", dans Hagiographie, idéologie et politique au Moyen Âge en Occident, BozoKy, Edina (dir.), Turnhout, 2012, p. 44 et Van UytFanghe, L'hagiographie en Occident [supra, n. 17], p. 32.

56. La fin du vi ${ }^{\mathrm{e}}$ siècle, avec Fortunat et Grégoire de Tours, est le moment où le miracle, qui avait suscité quelques réserves chez les Pères et chez les moines, l'emporte définitivement, " devient non seulement possible mais encore unanimement accepté et reconnu " (VAN UYTFANGHE, "La controverse biblique et patristique, autour du miracle ", Hagiographies, cultures et sociétés. Actes du colloque organisé à Nanterre et à Paris, 2-5 mai 1979, [par l'] université de Paris 10, Centre de recherches sur l'Antiquité tardive et le haut Moyen Âge, Paris, Études augustiniennes,1981, p. 216-217).

57. FAUQUIER, op. cit. [supra, n. 22], p. 676. Le miracle remplace le martyre.

58. DierKens, Alain, "Réflexions sur le miracle au haut Moyen Âge ", dans Miracles, prodiges et merveilles au Moyen Âge. Actes du XXVe congrès de la Société des historiens de l'enseignement supérieur public tenu à Orléans en juin 1994, Paris,1995, p. 20.

59. Cette répartition inégale se retrouve dans d'autres vitae, notamment dans la Vie de saint Germain où l'on compte 55 miracles postérieurs à l'élévation épiscopale.

60. C'est la résurrection du catéchumène après l'installation de Martin à Ligugé : SulPICE SÉVÈRE, Vita Martini, 7, 2-5, éd. / trad. Jacques FonTAINE, Vie de saint Martin, I [supra, n. 33], p. 267-269. 
Vita Hilarii ${ }^{61}$. Douze autres miracles, la grande majorité, sont des miracles de guérison ou de libération de captifs. La libération de prisonniers est encore un thème d'inspiration martinienne ${ }^{62}$ qu'on rencontre à deux reprises dans la Vita Albini : une première fois aux chapitres 33-34 qui rapportent le rachat d'une prisonnière noble, l'illustre Aethérie. L'évêque s'oppose à l'ordre établi, puisque la femme " est poursuivie par le roi " et gardée par des soldats du souverain. La résistance de l'un d'entre eux à la volonté du saint entraîne sa mort. Mais saint Aubin préfère ne pas risquer le courroux royal et paie le prix du rachat de la prisonnière au souverain ${ }^{63}$. Le miracle de libération s'accompagne ainsi d'un miracle de châtiment ${ }^{64}$, ailleurs d'une affirmation de l'autorité épiscopale face à un " juge " qui refuse de libérer des captifs emprisonnés dans une tour de l'enceinte ${ }^{65}$.

Les miracles de guérison, de loin les plus nombreux, ce qui n'a rien de surprenant ${ }^{66}$, ne sont pas d'une grande variété. On rencontre une femme dont "les mains sont contractées par l'infirmité de ses nerfs engourdis" qui ressemble beaucoup à la jeune fille guérie par les reliques d'Hilaire dans le De virtutibus sancti Hilarii ${ }^{67}$. Les autres miracles de guérison concernent presque tous l'œil. Trois aveugles retrouvent la lumière aux chapitres 30-32,

61. Vita Hilarii, c. 42, éd. KRuSch, $M G H, A A$, IV 2, p. 5 : Revenu à Poitiers, à son retour d'exil, " tandis qu'il avait prescrit au bienheureux Martin de s'établir dans le village de Ligugé, la vertu divine lui accorda de ressusciter un mort. Quelques jours après, en effet, un petit enfant privé de la régénération du baptême décéda : condamné à une mort double, il avait perdu la lumière d'ici-bas, et n'était pas exempté du châtiment des temps futurs".

62. Sulpice SÉvère, Gallus. Dialogues sur les “ vertus » de saint Martin, III, 4, 1-7, Introduction, texte critique, traduction et notes par FonTAINE, Jacques, avec la collaboration de DupRÉ, Nicole, Paris, 2006 (Sources chrétiennes, 510), p. 301-307.

63. Le rachat des captifs fait partie des devoirs des évêques qui trouvent dans cette pratique charitable ainsi que dans la libération des prisonniers un moyen "d'étendre les liens de clientela et de renforcer leur statut de patrons locaux " (KLINGSHIRN, William, "Charity and Power : Caesarius of Arles and the Ransoming of Captives in Sub-Roman Gaul ", The Journal of Roman Studies, vol. LXxv (1985), p. 183-203, ici p. 183). Le canon 5 du concile d'Orléans de 511 permet aux évêques de dépenser les revenus des églises pour "l'entretien des évêques et des pauvres et le rachat des captifs." (Les canons des conciles mérovingiens, t. I [supra, n. 40], p. 76-77; mêmes dispositions dans le concile de Mâcon II de 585, canon 5, op. cit., t. II, p. 162-163). Grégoire de Tours rapporte comment l'évêque Marovée se racheta lui et la population de la ville en brisant un "calice d'or faisant partie des vases sacrés " (Decem libri historiarum, VII, 24, éd. KRUSCH, mgh, srm Ibis [supra, n. 5], p. 344.

64. Les miracles de châtiment sont encore peu nombreux à cette époque sauf dans le monde irlandais. BOZOKY, Edina, " Les miracles de châtiment au haut Moyen Âge et à l'époque féodale ", dans Violence et religion, CAZIER P. et Delmaire J. (dir.), Lille, 1998 (Coll. Travaux et recherches), p. 151-158.

65. C. 44. Voir OudART H., "L'évêque défenseur des pauvres, correcteur des injustices, libérateur des prisonniers dans les œuvres de Venance Fortunat " [http://www.paris-sorbonne.fr/IMG/pdf/3Oudart-Camenae.pdf].

66. FAUQUIER, La sainteté à la fin de l'Antiquité [supra, n. 22], p. 628 sqq., a calculé que les miracles de guérison et de résurrection représentaient $45 \%$ du total des miracles.

67. VenAnCE, FoRTunAt, Liber de virtutibus sancti Hilarii, c. 15, éd. KRUSCH [supra, n. 2], p. 9. 
un autre au chapitre 43 et le dernier aux chapitres 36-37, guéri à la fois de sa cécité et d'une possession diabolique qui le fait se tordre de douleur. Il s'y ajoute la phlébotomie miraculeuse d'un œdème qui s'était formé sur l'œil d'une femme possédée par l'Ennemi ${ }^{68}$ et le miracle posthume accompli par saint Aubin, lors de la première translation de ses reliques, qui guérit trois paralytiques et deux aveugles qui " pareillement rendus à la lumière, reçurent enfin la clarté du jour de l'ombre du défunt " (c. 58). Les récits de Fortunat ne permettent guère d'analyser les caractères précis de l'infirmité, encore moins de connaître l'origine sociale des aveugles. Le processus de guérison ne met pas l'accent sur la puissance thaumaturgique du saint mais plutôt sur les méthodes qu'il emploie pour susciter l'intervention divine. Ce sont la prière et la croix. Pour ressusciter un mort, Aubin prie longuement, " étendu dans la poussière ${ }^{69}$ ". Déjà dans la Vita s. Hilarii, Hilaire faisait appel à la croix pour purger l'île de Gallinara des serpents qui l'envahissaient ${ }^{70}$, comme l'avait fait Martin lui-même. C'est encore le signum crucis dont use Radegonde pour guérir un aveugle ${ }^{71}$. Ici encore c'est la croix, le signe ou le sceau de la croix qui repoussent le mal ${ }^{72}$, comme on le voit bien au chapitre 38 : «De même à Angers, lorsqu'un certain Maurille demanda que la lumière fût rendue à ses yeux clos, l'évêque, recourant alors à ses armes bien connues, traça aussitôt le signe vénérable sur ses paupières et, comme un projectile très puissant, la croix pénétra les ténèbres et apporta derrière elle la lumière à l'aveugle. " On connaît la dévotion à la Croix de Fortunat, surtout depuis l'arrivée de la relique de la Croix à Poitiers le 19 novembre 569 , accueillie par le Vexilla regis, dans les lieux où avait triomphé la foi trinitaire que Fortunat n'a cessé de chanter. Mais l'emploi répété dans la Vita Albini des deux armes du saint - la croix et la prière - prend un caractère presque rituel $^{73}$.

68. Il n'est pas dit que la possession diabolique résulte d'une faute commise par l'aveugle. Les autres cécités paraissent aussi naturelles.

69. c. 28. La prière est également mentionnée au c. 42. Au c. 45, les murs de la prison s'écroulent sous l'effet de la prière.

70. Vita s. Hilarii, 35, éd. Krusch [supra, n. 2], p. 5 : " À ces mots l'homme de Dieu, sentant que la victoire reviendrait dans une lutte contre la bête, au nom du Seigneur, se faisant précéder de l'aide de la Croix, débarque sur l'île. "

71. Vita s. Radegundis, I, 27, MGH, SRM [supra, n. 2], p. 375, 1. 24 : signum crucis impressit, caecitas fugit, lux rediit.

72. c. $26,27,30,31,32,43$, 45. Jacques Fontaine a bien montré comment le signe de la croix - signum crucis, signun salutis - est devenu, chez les Pères du Désert comme chez Martin, un " geste apotropaïque efficace contre les puissances du Mal " (FonTAINe, Vie de saint Martin, I [supra, n. 33], p. 165-166). La dévotion à la croix est manifeste chez Fortunat, comme le montrent les poèmes à la croix regroupés au début du livre II des Carmina (i, ii, iii, iv, v), éd. LEO, p. 27-33. Les deux plus célèbres, le Vexilla regis et le Pange lingua gloriosi lauream certaminis, ont été composés à l'occasion de l'arrivée des reliques de la Croix à Poitiers, à l'époque de la rédaction de la Vita s. Albini.

73. Voir DölgER, F. J., "Beiträge zur Geschichte des Kreuzzeichens ", Jahrbuch für Antike und Christentum, 4 (1961), p. 14 sqq. On peut relever que dans la Vita Albini Fortunat ne fait pas appel à d'autres armes telles que l'onction, la réception du pain consacré. C'est avec Constantin que la croix devint la croix victorieuse et que les voûtes d'édifices chrétiens familiers à Fortunat, Saint-Vital de Ravenne, Saint-Apollinaire in Classe, 
Un autre aspect qu'il convient de retenir est l'introduction à la fin de la Vita de miracles post mortem, survenus lors la première translation miraculeuse des reliques du saint, dans la nouvelle basilique Saint-Aubin, présidée par saint Germain de Paris et d'autres évêques. C'est le " témoignage du bienheureux Aubin vivant après sa mort, car, bien que son corps soit enfermé dans la tombe, cependant la récompense de l'âme du juste a produit une grande abondance de fruits " (c. 54), notamment la guérison des deux paralytiques et des deux aveugles.

L'attirance de Fortunat pour la thaumaturgie ophtalmique ne s'explique sans doute pas seulement par les ennuis oculaires dont a souffert le poète italien dans sa jeunesse à Ravenne ${ }^{74}$, ni par la fréquence des guérisons d'aveugles dans les corpus hagiographiques ${ }^{75}$. Il faut y voir plutôt une sorte de jeu rhétorique sur l'opposition entre les " ténèbres ", le "brouillard " ou la " nuit " de la cécité et la lumière qui inonde les yeux des laïcs ${ }^{76}$ ou du moine Gennomer : " la splendeur vivifiante de la lumière pénétra ses yeux, chassa les ténèbres et le soleil qui lui était étranger resplendit en lui ". Mais cette rhétorique n'est pas un simple jeu. Fortunat met l'éclat de sa rhétorique au service d'une théologie de la lumière. Cette lumière, c'est celle du Christ, " lumière du monde " dans la guérison de l'aveugle-né ${ }^{77}$. Dans un article pénétrant, Geneviève Bührer-Thierry a montré l'importance du vocabulaire dans l'œuvre poétique de Fortunat ${ }^{78}$. Sans être le phare de l'humanité comme saint Martin dans la Vita en vers de l'évêque de Tours ${ }^{79}$, Aubin est porteur de la lumière du Christ. Peut-être l'aveugle dans la vie de saint Aubin n'est-il que le symbole de l'homme arraché aux ténèbres de la nuit par la foi baptismale : l'aveugle guéri au monastère d'Asiagus est "illuminé par sa foi ${ }^{80}$ ". Les œuvres de Fortunat ne sont pas

s'ornent de grandes croix. La croix est bien pour Fortunat un symbole de victoire, comme il l'explique dans l'Exposition du symbole au début du Livre XI des Carmina (XI, 21, éd. REYDELLET, t. III, p. 106-107 : " La croix est une espèce de trophée que l'on a l'habitude de confectionner pour le Triomphateur, une fois les ennemis défaits, et parce que le Seigneur s'est soumis trois royaumes, suspendu en l'air. Il a remporté la victoire sur les puissances mauvaises..." ").

74. Dans les miracles de saint Hilaire, on ne compte qu'une seule guérison d'aveugle (c. 17, éd. Krusch, Auctores Antiquissimi, IV 2 [supra, n. 37], p. 9).

75. SigAL, André, L'homme et le miracle dans la France médiévale (XI ${ }^{e}-X I I^{e}$ siècle), Paris, 1985, p. 228 : les guérisons ophtalmiques représentent 17,5\% de l'ensemble des guérisons.

76. C. $30,31,32,37,58$.

77. Jn 9, 5. Voir aussi Jn 8, 12 : « Jésus leur parla de nouveau, et dit : Je suis la lumière du monde; celui qui me suit ne marchera pas dans les ténèbres, mais il aura la lumière de la vie " ou encore la parabole de la lampe dans Lc 11, 33-35.

78. BÜHRER-THIERRY, Geneviève, "Entre panégyrique antique et théologie de la lumière " [supra, n. 26], p. 147-154. L'auteure note justement (p. 148, n. 10) que Marc Reydellet (Venance Fortunat. Poèmes, Livres i-iv, Paris, 1994, p. LVI, n. 184) a relevé la prédilection de Fortunat pour le vocabulaire de la lumière, notamment les verbes micare, fulgere, splendere, coruscare. On pourrait ajouter à la liste le verbe rubescere. On en voit un autre exemple dans la Vita s. Medardi, en vers, parfois attribuée à Fortunat, Patrologie latine, t. 88, col. 114 : Tercia lux rediens nocturnas solverat umbras et caeco occurrit sic revocata dies.

79. Vie de saint Martin, éd. et trad. par QuESNEL [supra, n. 1], p. XLII sqq.

80. C. 30 . 
" des œuvres de pure circonstance [...] des exercices de style [...] exécutés sans conviction personnelle profonde ${ }^{81}$ ". Les feux de la rhétorique chez Fortunat ne sont pas seulement des feux d'artifices tirés pour éblouir des commanditaires. Et c'est pourquoi sans doute son œuvre a été admirée par son contemporain Grégoire de Tours, et par de grands auteurs médiévaux de Paul Diacre ${ }^{82}$ à Dante ${ }^{83}$. Cette admiration est d'autant plus justifiée que l'œuvre ne concerne pas seulement un public cultivé de clercs et de moines mais s'adresse aussi au peuple pour l'édification duquel elle a été écrite. C'est ce double langage qui est subtilement évoqué dans le long prologue qu'adresse Fortunat à l'évêque d'Angers Domitianus. L'éloge obéit parfaitement aux usages d'une rhétorique subtile ${ }^{84}$ croisant les lumières du dédicataire, l'évêque-maître, le dévouement et " l'élégance " du témoindisciple $^{85}$, les protestations d'incompétence de l'hagiographe. Si ce dernier au chapitre 6 se plaît à déballer ses défauts et à se dévaloriser, c'est à la fois pour mieux magnifier les qualités de rhéteur et "l'habileté " du prélat, mais aussi pour préparer la suite du discours, un discours de rustre - sermo rusticus - quelque chose de plus compréhensible qui parvienne aux oreilles du peuple (c. 8), " de telle sorte que le récit exceptionnel de la vie d'un saint homme devienne un remède public pour tous ceux qui l'écoutent ${ }^{86}$ ". La phrase paraît indiquer que Fortunat s'efforce d'adopter

81. PIÉTRI, Luce, "Venance Fortunat et ses commanditaires. Le poète italien dans la société gallo-franque ", dans Commitenti e produzione artistico letteraria, Settimane di studio del Centro italiano di studi sull Alto Medioevo, xxxix, Spolète, 1992, p. 729-759, ici p. 747. Dans cet article, Luce Pietri, après Marc Reydellet et beaucoup d'autres chercheurs, a voulu réhabiliter cet immigré ambitieux, ce " rital ", en quête de commanditaires, rois, princesses, évêques, prêtres, abbés, qui a su s'adapter et même s'intégrer à sa " patrie " d'adoption.

82. De gestis Langobardorum, II, 13, Patrologie latine, t. 95, col. 489 et Histoire des Lombards, trad. Bougard, François, Turnhout, Brepols, 1994 (Miroir du Moyen Âge), p. 43-44.

83. PIÉTRI, "Venance Fortunat et ses commenditaires ", [supra, n. 81], p. 733.

84. Ce "galimatias " de flatteries raffinées, qui peut troubler le lecteur contemporain. plonge ses racines dans la rhétorique antique. Voir L'HuILLIER, M.-Cl., L'Empire des mots. Orateurs gaulois et empereurs romains [IIt - IV siècle], Paris, les Belles-Lettres, 1992 et PERNOT, Laurent, La rhétorique de l'éloge dans le monde gréco-romain, Paris, 1994; ID. La rhétorique dans l'Antiquité [supra, n. 16], ainsi que Goullet, Monique, "La Laudatio sanctorum dans le haut Moyen Âge. Entre vita et éloge ", dans MARY, L. et SoT, M. (dir.), Le discours d'éloge entre Antiquité et haut Moyen Âge, Paris, 2001. Paul Diacre reconnaît à Fortunat " une très grande notoriété dans l'art de la grammaire, dans celui de la rhétorique et même en poésie ". Fortunat, on l'a dit, " aimait l'éloge; il en prodiguait à profusion aux évêques et princes" (QuESNEL, Vie de saint Martin [supra, n. 1], p. xlvii). Ces éloges plaisaient aux lecteurs de Fortunat et ont influencé pendant des siècles les prologues des vies de saints et les préfaces des œuvres profanes. Le but en était clair : établir la supériorité du destinataire, consolider le pouvoir établi - ici le pouvoir épiscopal - pour mieux profiter de la protection des puissants.

85. C. 5 : «Tout ce qui vient de lui en vérité doit être rapporté à votre éloge, puisque la louange faite au disciple est le mérite du maître et le secours du serviteur l'ornement du pontife."

86. C. 1. Voir sur ce point les remarques de Richard Collins (" Observations on the Form » [supra, n. 1], p. 106-109), qui s'appuie sur des passages de la Vita Hilarii, 1 [supra, 
un style moins relevé dans ses œuvres hagiographiques pour s'adresser à un large public ${ }^{87}$ incapable de saisir les réminiscences classiques et les références bibliques ${ }^{88}$. Il ne faut cependant pas se laisser abuser par cette affectation de rusticité. Dans les chapitres de la Vita, la rhétorique est loin d'être absente. Chaque épisode fait l'objet d'une notice ciselée comme dans un médaillon de figures de rhétorique ${ }^{89}$. Il suffit d'avoir affronté la traduction de ce texte pour se rendre compte de la sophistication d'un style marqué par la vigueur des oppositions et la recherche de formules brillantes ${ }^{90}$, le recours à des effets d'accumulation ou de redondance ${ }^{91}$. La vigueur des formules flattait l'auditeur lettré, elle capte encore aujourd'hui l'admiration d'un lecteur moderne amoureux des mots. Mais Fortunat n'oublie pas un public avide de miracles. C'est en partie pour cette raison qu'ils tiennent une place prépondérante dans la Vita et que certains de ces miracles ont un contenu qu'on pourrait qualifier de " populaire " ou de " folklorique " ${ }^{92}$. C'est le cas au chapitre 19 de la chaumière noyée par la pluie qui épargne le saint. Mais en même temps une pointe de préciosité permet de piquer l'attention d'un auditoire plus cultivé : « la pluie craignit de frapper Aubin parce que là où l'eau sent la flamme de la foi, elle se détourne pour ne pas lui faire injure ". L'hagiographe ne s'adresse pas seulement aux moines et aux évêques mais aussi aux laïcs. Le style mixte permet sans doute de fédérer des publics divers, on n'y sent même pas la connivence amicale qui unit le poète italien à l'évêque Félix dans les Carmina.

L'image que Fortunat donne ici d'Aubin est celle d'un saint idéal qui obéit au modèle de sainteté monastico-épiscopale introduit par Sulpice Sévère dans sa Vie de saint Martin, approfondi et diffusé par la vie de saint Germain d'Auxerre dont Michel Fauquier a récemment montré l'impor-

n. 61] et de la Vita s. Medardi, considérée comme une œuvre de Fortunat (Patrologie latine, t. 88, col. 110-116).

87. Déjà à la fin du ve siècle, des hagiographes " disent qu'ils ont cherché à écrire plus simplement " (RICHÉ Pierre, Éducation et culture dans l'Occident barbare, VI ${ }^{e}$-VIII siècles, Paris, 1962, p. 131 sqq.).

88. Voir à ce sujet les tableaux de FAUQUIER, op. cit. [supra, n. 22], p. 161 et n. 1. Il y a seulement $0,80 \%$ de références bibliques dans la Vita Albini. Une des raisons pourrait être la volonté de l'auteur de développer " un discours propre ", " auto-suffisant ".

89. Fortunat, à son habitude, se sert de l'énumération pour créer un effet de surprise (c. 6, 15, 16 17, 25 etc). Il recourt à l'hyperbole (c. 1 : quae sensus vester torrentis more mihi visus est inundare). Pour indiquer la noblesse des origines d'Aubin, il utilise la comparaison avec la plante au c. 11 : immo digni germinis dignissima proles emergens. S’il abuse parfois de métaphores usées (c. 9), elles s'inscrivent souvent dans une phrase qui en relève l'effet en le prolongeant : eo quod in flore adolescentiae virtutis odore fragraret (c. 20 ).

90. C. 13 : " en ce lieu, lui que la naissance fit naître libre, sa volonté le fit esclave "; c. 32 : "le brouillard de la cécité ", etc, qu'il use des antithèses, par exemple au c. 17 : "même quand il parut en public, il resta toujours enfermé dans la prison de son cœur ", au c. 57 : "reçurent enfin la clarté du jour de l'ombre du défunt " et au c. 41 : " rapporter l'histoire vivante d'un cadavre".

91. C. $15,17,22,25$, etc.

92. La constatation a déjà été faite par Collins, "Observations on the Form " [supra, n. 1], p. 112. Ces miracles ont aussi une dimension pédagogique et constituent, du moins en apparence, une sorte de " catéchèse rudimentaire ", selon la formule d'André Vauchez. 
tance ${ }^{93}$ et retouché par Fortunat qui accorde une grande importance à la rhétorique, insiste sur les miracles qui rendent immédiatement présente la puissance miraculeuse du saint et garde le silence sur ses défauts ${ }^{94}$.

Même si Fortunat est fort habile à dissimuler les défauts de ses héros, on devine cependant que ce saint presque parfait a parfois été en butte à des conflits sérieux avec les agents du roi ${ }^{95}$, avec les évêques ${ }^{96}$ réunis en concile à Orléans, conflits que Fortunat préfère étouffer par un miracle ${ }^{97}$.

Contrairement à la Vita s. Radegundis, la Vita s. Albini est une œuvre de commande. L'émotion que laissera percer le poète exilé à Poitiers pour les vertus de la princesse thuringienne et les épreuves qu'elle s'est imposées est presque absente de la Vie de saint Aubin ${ }^{98}$. On en trouve cependant la trace dans l'évocation de la peine que ressent saint Aubin à la mort d'un " tendre adolescent déjà entré dans la vie monastique qu'il aimait particulièrement pour la qualité de ses mœurs " (c. 41). Ce n'est pas l'émotion qu'a cherché Fortunat dans cette Vie. C'est à travers la sobriété de chaque récit que se révèle l'éclat de la sainteté.

\section{Vie de saint Aubin, évêque d'Angers}

1. Au seigneur saint qu'il faut célébrer avec le plus grand respect en raison de ses mérites apostoliques, le seigneur évêque Domitien ${ }^{99}$, votre Fortunat. Je me souviens, homme apostolique, que, me rendant à la ville que vous dirigez sous la conduite du Christ pour me présenter à vos regards, parmi tous les autres projets mûrement réfléchis dont je me suis vu submergé par votre intelligence comme par un torrent, vous avez suggéré discrètement que la vie du très saint Aubin, votre prédécesseur dans l'épiscopat, dont il est prouvé que la vie gravée dans les actes célestes fleurit en mérites qui ne se flétrissent point, soit aussi fixée dans les écrits des hommes et établie pour l'édification du peuple : le peuple la consultera avec un double bienfait puisque, voyant en lui des choses admirables à vénérer et considérant en lui-même ce que chacun doit corriger avec sagacité, connaissant ainsi chez un seul tant de choses recommandables, chacun ne tarde pas à tailler en lui les rameaux des vices, de telle sorte que

93. FAUQUIER, La sainteté à la fin de l'Antiquité [supra, n. 22], p. 362.

94. Ibid., p. 367-370.

95. Voir c. 33-34.

96. FAUQUIER, La sainteté à la fin de l'Antiquité [supra, n. 22], p. 362.

97. Il n'est pas impossible que les dissensions du concile d'Orléans aient eu des prolongements jusqu'à la mort d'Aubin.

98. On ne sent pas l'effroi qui saisira Fortunat lorsqu'il évoquera aux chapitres 25 et 26 de la Vita $s$. Radegundis les horribles supplices que la sainte s'infligeait à ellemême : "Aussi après tant de labeurs, celui qui vous parle ici frémit-il de rapporter les peines qu'elle allait s'infliger. "Voir Pon, Georges, "Un corps martyrisé : l'exemple de Radegonde ", Corps outragés, corps ravagés, de l'Antiquité au Moyen Âge, dans Bodiou Lydie, SoRia Myriam, MeHL Véronique, Turnhout, Brepols, 2011, p. 249-259.

99. Domitien, évêque d'Angers, successeur d'Aubin (voir la notice de DuchEsNe Louis, Fastes épiscopaux de l'ancienne Gaule, t. II, Paris, 1910, p. 358). 
le récit exceptionnel de la vie du saint homme devienne un remède public pour tous ceux qui l'écoutent.

2. Vous comprenez bien que ceux qui ont quitté le siècle sont vite arrachés à la mémoire et que si on néglige de fixer par écrit quelques épisodes de la vie d'un si grand saint destinés à s'effacer rapidement, il n'est pas facile de faire revenir à l'esprit ce qui aura déjà commencé à disparaître dans l'oubli envahissant du temps [qui passe].

3. Par la suite ${ }^{100}$, conformément aux ordres de votre béatitude, quelqu'un m'incita très vivement à le faire sans délai, si du moins j'y consentais. Et il ajouta que ce qu'il avait lui-même appris de bonne source des actions de saint Aubin, il me le confierait et que moi, à son instigation, je le rendrais public de manière certaine : ce qui l'affligeait le plus profondément dans cette affaire, c'est que les actions que le susdit saint avait accomplies certes en secret mais dignes d'être rapportées, il n'avait pas été capable de les découvrir toutes par une recherche attentive de la vérité et que pour celles qui lui avaient été connues, quelques-unes s'étaient effacées de sa mémoire.

4. Mais pour celles qu'il se rappelait nettement, il nous fournit des gens qui confirmaient son témoignage, car en vérité il n'est pas permis de jeter le doute sur la vie passée de celui qui opère chaque jour les actions les plus éclatantes en toute chose.

5. J'ai d'autant plus félicité le narrateur que cet homme a été nourri par vous dans son adolescence, qu'il exposait avec tant de force ce qui lui avait été ordonné et qu'il offrait en raison de son élégance quelque chose de son propre fonds qui n'était pas déplacé; bien plus lui-même exposait avec limpidité par ses propres mots ce qu'il avait demandé à autrui. Tout ce qui vient de lui en vérité doit être rapporté à votre éloge, puisque la louange faite au disciple est le mérite du maître et le secours du serviteur, l'ornement du pontife.

6. Dans ma petitesse je tremblais d'aborder ce sujet, sachant bien qu'il devait l'être par des gens remarquables par le talent, éloquents dans le discours, dévoués à leur tâche, estimés pour leur style, des hommes riches de jugement, impétueux dans leurs effets de langue, rapides à la servir, flamboyants dans la versification; sachant que face à votre habileté, je m'en doute, l'éloquence même de Cicéron courrait d'un pied à peine sûr et que face à vous, Rome plaidant une cause craindrait peut-être la Gaule devant un juge aquitain ${ }^{101}$, j'ai senti qu'il était inconvenant qu'on me réclamât un sujet élevé, à moi qui me cache sous les traces des gens instruits : la nature ne m'a pas donné de facilité pour écrire, ni la grammaire de l'éloquence, ni

100. On peut aussi traduire postmodum par " peu après ".

101. Fortunat glisse habilement d'un discours général sur la richesse rhétorique à l'éloge direct de Domitien (votre habileté, face à vous) pour mieux présenter l'évêque d'Angers comme un savant rhéteur, sur le modèle du haut fonctionnaire de l'Empire romain tardif. Collins " Observations on the Form " [supra, n. 1], p. 109-110 insiste justement sur ce point en citant les travaux de M. Heinzelmann sur les épitaphes épiscopales de l'aristocratie gallo-romaine, Bischofsherrschaft in Gallien [supra, n. 27], p. 120. 
même une pratique incessante, de l'aisance ; même si je suis engagé par ma promesse, je tremble devant la grandeur de ma tâche, car une Vie brillante est souillée par la langue insuffisante d'un écrivain paresseux qui cache sous la nuée du discours ce qu'il devrait faire briller ${ }^{102}$. Il aurait mieux valu qu'au lieu de demander cette œuvre à autrui, vous la produisiez vousmême.

7. Certes, je comprends parfaitement que vous ne pouvez vous charger d'un tel travail mais que vous avez voulu que notre besace ne vous refuse rien, même de ce qui est étranger, comme si les orges de ma stérilité pouvaient apporter quelque chose au milieu des fruits du froment.

8. Aussi désormais, suspendant les raisons de mon doute dans la balance du jugement, je choisis d'être reconnu pour un rustre par obéissance plutôt que de manquer de respect par principe, de telle sorte que vous approuviez au moins l'affection de celui dont vous pourriez mépriser le discours et afin qu'en vérité, dans cet ouvrage, quelque chose de plus compréhensible parvienne de mon fait aux oreilles du peuple.

9. C'est pourquoi m'appliquant de toute ma médiocrité et bien que je sois un auteur maladroit, je désire cependant faire connaître brièvement l'histoire d'une vie bienheureuse : il reste à Celui qui sait que je préférais obéir plutôt que de présumer de mes forces de fournir Lui-même à mon écrit fluctuant le port de sa droite, ce Dieu qui vit et règne dans les siècles des siècles. Amen.

10. Plus la vie des hommes religieux brille de mérites, plus elle est répétée par la voix du peuple parce qu'en distribuant à tous les bonnes actions accomplies, elle incite les voix de chacun à la louange du saint : c'est à quoi on parviendra très clairement en rendant publics la vie et les actes du très bienheureux ${ }^{103}$ Aubin.

11. Donc ${ }^{104}$ l'évêque Aubin, originaire du pays de Vannes aux confins de l'Océan britannique ${ }^{105}$, naquit de parents qui n'étaient pas de modeste extraction mais plutôt issus d'une très noble race ${ }^{106}$ : l'honneur qu'il reçut

102. Ces protestations d'incompétence, conformes aux habitudes de la rhétorique antique, sont habituelles chez Fortunat. Il suffit de renvoyer au passage de la Vita Martini où Fortunat se dit lui-même " pauvre d'intelligence " etc. C'est aussi une façon délicate d'annoncer que dans la suite du texte il va employer un registre de langue moins recherché, un sermo rusticus : ne dit-il pas au chapitre 8 : "eligo rusticus agnosci, je choisis d'être reconnu pour un rustre "?

103. Sanctus, beatus, sanctissimus, beatissimus sont à peu près synonymes (FAUQUIER, La sainteté à la fin de l'Antiquité [supra, Introduction, n. 22], p. 72).

104. L'adverbe Igitur marque le début de la Vita proprement dite. Cet emploi sera repris par les hagiographes du haut Moyen Âge.

105. Aubin est né vers 469. Sur son lieu de naissance, voir supra, n. 6.

106. Sur la noblesse du saint, voir Introduction. Le nouveau thème de la naissance noble est fréquent dans l'œuvre en vers de Fortunat. Leontius de Bordeaux est dit nobilitate potens et clarus ab antiquis. Comme l'a relevé Collins, "Observations on the Form », p. 114, l'association noblesse / épiscopat - la noblesse qui illumine l'épiscopat et l'épiscopat qui renforce la noblesse - « se retrouve dans beaucoup d'autres représentations de la sainteté gallo-romaine ". L'idée a été souvent reprise par Fortunat (voir par exemple un des 
de sa noble ascendance, il l'augmenta par les mérites de sa vie bienheureuse, car en lui le Christ a choisi ce qu'll glorifierait ${ }^{107}$ et fait resplendir ce que le monde doit vénérer.

12. En lui, dans les débuts d'une tendre jeunesse, brilla une telle ferveur de foi qu'il a préféré pour l'amour du Christ abandonner des parents ${ }^{108}$ dont l'enfance d'habitude ne cesse d'avoir un besoin pressant et qu'il a fui les affections charnelles comme des ennemis de l'âme, croyant qu'il lui suffisait de planter toute son affection dans le Père céleste seul.

13. Bientôt, dans le monastère de Tintilliacense ${ }^{109}$, il s'est soumis pour plaire au Seigneur avec une telle humilité d'esprit que, l'honnêteté de ses mœurs exceptée, il ne revendiquait rien pour lui du privilège d'être de bonne famille ${ }^{110}$ et, en ce lieu, lui que la naissance fit naître libre, sa volonté le fit esclave, car il comprenait qu'il était plus digne de louange que, par amour du Christ, sa noblesse abaissât ce qu'il était plutôt que de chercher avec morgue à apparaître pour ce qu'il n'était pas.

14. Enfin la pratique de l'ascèse quotidienne ${ }^{111}$ lui était si utile que, s'élevant toujours par ses mérites, il ne l'emportait pas sur les autres, mais plutôt triomphait de lui-même en domptant entièrement son corps.

15. Qui pourra en effet raconter combien il l'emportait par la sobriété de ses jeûnes, combien il était porté au plaisir des veilles, combien il méritait d'éloges par son assiduité à la prière, combien il était exceptionnel dans l'œuvre de la compassion ${ }^{112}$, tant et si bien qu'il écrasait l'Ennemi qui lui résistait et qu'ainsi ce que seul il s'infligeait à lui-même devenait pour tous les autres le plus grand des espoirs?

16. Il était en effet prompt à l'obéissance, résolu à piétiner les vices, de sorte que dès son apprentissage juvénile même il était déjà un exemple

poèmes à l'évêque de Nantes Félix; qui terrena de noblitate nitebas, / ecclesiam nunc spe nobiliore regis, Carmina, III, 8, éd. LEO, F., $m g h$, a a, IV, 2, Berlin, 1881, p. 58 et éd. REYDELLET, Poèmes, [supra, n. 6], t. I, p. 98, l. 25).

107. Théologiquement c'est le Christ qui glorifie, comme l'enseigne la prière de Jn $(17,1)$ : "Père, l'heure est venue : glorifie ton Fils pour que ton Fils te glorifie. "

108. La rupture avec les parents vient de l'enseignement de Jésus mais aussi de l'exemple martinien (Vita Martini, II, 1-4, éd. / trad. FonTAINE, Vie de saint Martin, I [supra, n. 33], p. 255).

109. Pour l'identification de ce monastère, voir la discussion dans l'Introduction, supra, n. 6.

110. Comme le remarque finement Michel FAUQUIER, La sainteté à la fin de l'Antiquité [supra, n. 22], p. 237, Fortunat fait ressortir ainsi à nouveau les origines sociales de saint Aubin.

111. Sur la révolution que constitue l'ascèse chrétienne, voir FAUQUIER, ibid., p. 471 sqq. et tout particulièrement la n. 4, p. 483 qui fonde l'ascèse sur la participation "à l'œuvre amorcée par la Passion et que chaque chrétien est appelé à accomplir dans sa chair " comme l'exprime saint Paul dans Col. 1, 24 : «J'accomplis ce qui manque à la souffrance du Christ, en ma chair, pour son corps qui est l'église." "

112. Miseratio semble ici employé dans un sens très proche de misericordia. FAUQUIER, ibid., p. 238, n. 4 en donne quelques exemples : Vita Honorati, 5, 6; 17, 8; Vitae patrum, IX, 2 etc. On notera qu'il n'est pas question parmi les œuvres de l'ascèse du travail manuel. 
pour les anciens et que, n'ayant rien de commun avec l'homme que le fait d'être né, il voulut pour tout le reste de sa vie n'appartenir qu'au Christ.

17. Pas d'œil pour la volupté, pas d'oreille pour les plaisanteries ${ }^{113}$, pas d'esprit porté à la légèreté, mais, réglant toujours sa conduite sur l'ancre de la gravité, il se conduisait toujours dans les limites de la clôture de telle manière que même quand il parut en public, il resta toujours enfermé dans la prison de son cœur et n'offrit à regarder en dehors de lui-même que le Christ qu'il portait fidèlement dans son cœur.

18. Dans le zèle qui l'absorbait, il parvint à un tel éclat de vie que le Seigneur témoigna au monde de ses services assidus par des miracles. Alors que, encore très jeune, il parcourait le pagus au service de son abbé et qu'il se consacrait à sa tâche chez quelque personne, une tempête éclata avec une telle violence et une si forte averse de pluie se mit à tomber que les toits ne pouvaient protéger la maison.

19. Et donc, comme la chaumière à cause de l'ampleur des précipitations se confondait avec le champ et que tous ceux qui se tenaient dans cette maison étaient trempés, la pluie craignit de frapper Aubin parce que là où l'eau sent la flamme de la foi, elle se détourne pour ne pas lui faire injure.

20. À cette vue, la sainteté, qui se dissimulait depuis des années dans le secret de son âme, se fit si bien connaître par ses mérites, que dans la fleur de son adolescence elle exhala l'odeur de la vertu ${ }^{114}$.

21. Ensuite, les dons célestes s'accroissant avec l'âge, vers trente-cinq ans, il est élu abbé et père pieux ${ }^{115}$ du monastère, lui qui en vérité, par son éclat, avait attiré à lui cette dignité. Cependant, sous la sévérité du maître, la discipline de la communauté refleurissait là où la liberté de pécher avait disparu grâce à une rigueur contraignante.

22. Tout brûlait d'égards pour la piété ${ }^{116}$, la psalmodie jaillissait pleine d'harmonie, le rayonnement de l'obéissance brillait parmi les frères, l'ornement de la sainte charité ${ }^{117}$ était au plus haut, parce que de même qu'il s'appliquait à arracher les vices, de même il s'efforçait de greffer les dons célestes.

113. LE Goff, Jacques, "Le rire dans les règles monastiques ", dans Haut Moyen Âge, culture, éducation et société. Études offertes à Pierre Riché, éd. Michel Sot, Nanterre, 1993, p. 93-103 et Moulinier, Laurence, " Quand le Malin fait de l'esprit. Le rire au Moyen Âge vu depuis l'hagiographie ", Annales, Histoire, Sciences sociales, mai-juin 1997, nº 3, p. 457-475 montre à partir d'exemples plus tardifs que le rire n'est pas le propre de l'homme et que le saint doit être sérieux.

114. L'odor virtutis est comme une odor sanctitatis, une odeur de sainteté qui émane du corps des saints bien avant leur mort, voir FAUQUIER, La sainteté à la fin de l'Antiquité [supra, n. 22], p. 261, qui cite de nombreux exemples, notamment l'odorem amoenissime suavitais des bonnes œuvres de Maxine de Riez († post 455).

115. L'adjectif pius pourrait aussi être synonyme de sanctus.

116. Il est difficile de savoir ce qu'il faut entendre ici par pietas. Le mot désignait en latin classique le respect des devoirs envers les dieux, les ancêtres, la patrie, et dans le latin des chrétiens toutes les nuances du respect que l'on doit avoir envers Dieu.

117. Entendons l'amour du prochain en Dieu. 
23. Dans cette fonction d'abbé, il gouverna avec bonheur la communauté qui lui avait été confiée pendant vingt-cinq ans.

24. Et parce que la renommée d'un aussi grand mérite ne reste pas ensevelie, mais que, portée par les ailes de plumes heureuses, elle remplit le monde entier, il arriva que la cité d'Angers fût dépouillée du gouvernement de son pasteur. Alors, du consentement universel du peuple auquel il résistait avec le zèle de l'humilité, il est élu dans la concorde au rang d'évêque sous la conduite du Christ ${ }^{118}$.

25. Il remplit comme il le devait la charge du sacerdoce et s'adonna aux aumônes des pauvres, à la défense des citoyens, à la visite des malades, au rachat des captifs, de telle sorte que l'action bienheureuse d'un seul devint le salut de tous et, par ce zèle, les vertus célestes fructifièrent en lui ${ }^{119}$.

26. Donc ${ }^{120}$, dans la cité d'Angers, alors qu'une femme nommée Grata s'était présentée à lui les mains contractées par l'infirmité de ses nerfs engourdis, il fit le signe de la croix sur la main droite infirme. Voici alors qu'une tiédeur vivifiante commença à se répandre dans sa paume déjà morte, puis, le jour suivant, elle se présenta à nouveau audit lieu pour y être marquée par lui du signe de la croix.

27. Après quoi, les veines commencèrent à reconnaître leur parcours : le troisième jour, dès qu'il l'eut marquée du sceau de la croix, aussitôt les tissus de ses doigts desséchés se relâchèrent et la femme se signa au nom du Christ de sa main droite ressuscitée dont elle avait retrouvé l'usage.

28. Une fois, alors que, passant par là, il était arrivé dans la bourgade de Gennes ${ }^{121}$, il découvre un adolescent, nommé Alabaudus, déjà privé des fonctions vitales. Entendant les parents se lamenter sur la mort de leur fils qui venait de se produire, il accourt et, pour relever vivant celui qui gisait mort, il se prosterne en prière et, s'y abîmant, il pria assez longtemps.

29. Tandis que l'évêque prosterné dans la poussière perdait toute couleur, la force vivifiante de son âme rougeoyait à l'intérieur de son corps jusqu'à ce que le ciel ébranlé, le Tartare s'ouvrant, le jeune homme eût été rappelé de la mort et l'évêque de sa prière.

30. Ensuite, alors qu'il visitait le monastère d'Asiagus ${ }^{122}$ avec une paternelle sollicitude, un aveugle déjà illuminé par la foi lui crie de venir à son secours : il lui imposa le remède de la sainte croix et l'aveugle reçut la lumière aussi vite qu'il l'avait réclamée.

118. En 529 .

119. Fortunat ne s'intéresse guère à l'action épiscopale de saint Aubin. Il a hâte d'en venir aux actions miraculeuses du saint. Sur l'image de l'évêque dans la Gaule des ve et $\mathrm{VI}^{\mathrm{e}}$ siècles, voir Consolino, F. E., "Ascesi e mondanità nella Gallia tardoantica " [supra, n. 28]. p. 143-167; voir aussi BEAUJARD, "Cités, évêques et martyrs en Gaule romaine " [supra, n. 3], p. 175-191.

120. Igitur marque le début des actions, entendons des miracles.

121. C. Doué-la-Fontaine, arr. Saumur, Maine-et-Loire.

122. Non identifié. 
31. De même à Angers, lorsqu'un certain Maurille demanda que la lumière fût rendue à ses yeux clos, l'évêque, recourant alors à ses armes bien connues, traça aussitôt le signe vénérable sur ses paupières : comme un projectile très puissant, la croix perça les ténèbres, apportant derrière elle la lumière à l'aveugle.

32. De même, Marcellin, après avoir passé environ une dizaine d'années dans le brouillard de la cécité, fut traîné auprès du bienheureux pontife : quand ce dernier traça sur ses yeux le signe de la croix vénérable, le sang jaillissant aussitôt, les ténèbres furent chassées et la lumière fut.

33. Il nous faut aussi raconter un fait mémorable. Alors que l'illustre Aethérie, poursuivie par ordre royal, était retenue prisonnière sous la garde de soldats dans la villa de Dullacense ${ }^{123}$, le saint pasteur, portant alors secours à la brebis en danger ${ }^{124}$, vient seul auprès d'elle pour que personne ne le sache : à sa vue, la femme, embrassant ses pieds ${ }^{125}$, s'accrochait à lui gémissante.

34. Alors que, dans son audace insensée, un malheureux garde veut comme un loup l'arracher au vêtement du pasteur, le saint homme perçut l'outrage. Il lui souffla alors au visage ${ }^{126}$ et l'agresseur de l'évêque fut frappé d'une mort rapide.

35. C'est pourquoi tous les autres soldats, frappés de terreur, manifestèrent du respect au pontife et le châtiment d'un seul les exempta de toute faute : il ne se sépara de la femme qu'après avoir payé lui-même au roi le prix de sa libération. Ainsi, en un même moment, le suppliant trouva le salut et le présomptueux la mort.

36. Et il ne faut assurément pas passer sous silence ce qu'on a fait vœu de transmettre à la mémoire. Avec le zèle d'une pieuse dévotion, le saint père arriva dans une bourgade appelée Albivia $^{127}$. Là, alors qu'un aveugle sollicitait auprès de lui l'œuvre de miséricorde ${ }^{128}$, voici que, prisonnier depuis peu des attaques du démon ${ }^{129}$, il se mit à se tordre de douleur.

37. Alors Aubin jeta son corps à terre pour la prière à laquelle il se livrait toujours avec une sainte dévotion de l'âme, rendit aux yeux la lumière qui leur avait été précédemment arrachée et chassa la peste de l'esprit immonde. Ô ineffable grâce de la piété! Alors qu'il lui était seulement demandé de quoi subsister, c'est un triple remède qui fut obtenu : il a donné la nourriture à l'indigent, la vue à l'aveugle et rendu le captif à la liberté ${ }^{130}$.

123. Non identifié.

124. Mt 10, 5, 18, 12; Lc 15, 4, 15, 6 .

125. Lc 7, 45 .

126. Peut-être souvenir de Jn 20, 22 : "Après ces paroles, il souffla sur eux, et leur dit :

Recevez le Saint-Esprit. "

127. Non identifié.

128. Entendons l'aumône.

129. Le démon est beaucoup moins présent dans la vie de saint Aubin que dans celles de sainte Radegonde ou de saint Germain. Voir cependant c. 47.

130. Peut-être allusion à Mt. 11, 2 et Lc 7, 2 . 
38. De même, tandis qu'il se rendait à Paris pour rencontrer le roi Childebert ${ }^{131}$, on annonce au pontife que le souverain allait quitter la cité le lendemain pour chasser. Il fait mander qu'il daigne l'attendre. Mais parce que le bienheureux Aubin était retardé par une infirmité physique, le susdit roi se hâta d'aller à sa rencontre : tant qu'il garda le chemin qui conduisait à l'évêque, il fit route promptement et avec bonheur.

39. Mais alors qu'il parvenait au carrefour de trois voies et qu'il voulait dévier de sa route, son cheval ne put faire un pas comme s'il était en métal fondu ${ }^{132}$. Le roi conjecturant que la faute incombait plus au cheval qu'à une cause [réelle], fit seller une autre monture, mais quand il le contraignit à prendre le même chemin ${ }^{133}$, le cheval en fut incapable, comme s'il était brisé dans son élan par l'obstacle d'un mur.

40. Le roi comprenant qu'il n'avait servi à rien de changer de monture s'il ne changeait de trajet, commença à apprendre d'un cheval en quoi l'homme pouvait pécher et l'intelligence humaine pouvait être corrigée par l'animal. Se détournant pour prendre la route qui menait à l'évêque, il commença à s'avancer avec joie comme si, arraché d'une fosse, il avait retrouvé le plat d'une douce campagne.

41. Il vaut la peine de rapporter une histoire vivante au sujet d'un cadavre. Cet homme apostolique, s'étant rendu dans la cité de Vannes, voulait faire revenir chez lui au son des psaumes le pauvre corps d'un de ses suivants, un tendre adolescent déjà entré dans la vie monastique (conversus), qu'il aimait tout particulièrement pour la qualité de ses mœurs, qui était mort et enseveli en ce lieu un an plus tôt.

42. Alors qu'il séjournait en ce lieu pour cette raison, des serviteurs voulurent déplacer le corps avant l'arrivée de l'évêque, mais il était alourdi d'un tel poids qu'ils auraient pu mettre sur la balance des membres de géant plutôt que de soulever le corps du petit garçon : on aurait cru que

131. Fortunat rapporte aussi un voyage de saint Pair à Paris à la prière du roi Childebert (Vita s. Paterni, c. 41-43, éd. cit. [supra, n. 15], p. 36) et la Vita Germani (c. 8, 23, éd. cit. [supra, n. 2], p. 378 et 386) multiplie les rencontres avec le souverain. La visite du saint au roi devient un topos de l'hagiographie mérovingienne, notamment en Poitou. Dans l'anecdote qui est rapportée ici, il n'y a aucune intention critique à l'égard du " pieux roi (pius rex) et prêtre " (rex atque sacerdos), que le poète a aussi célébré dans le poème intitulé De ecclesia Parisiaca (Carmina, II, 10, éd. REYDELLET, I [supra, n. 6], p. 66-67). Voir DEGL'InNOCENTI, "L'opera agiografica di Venanzio Fortunato » [supra, n. 1], p. 142 et OUdART, Hervé, "Rex atque sacerdos. Un roi mérovingien "prêtre" dans le De ecclesia Parisiaca de Venance Fortunat ", Foi chrétienne et églises dans le société politique de l'Occident du Haut Moyen Âge (IV $\mathrm{e}^{\mathrm{e}}$-XII $\mathrm{e}$ siècle), textes réunis par HoAREAU-Dodinau, Jacqueline et TeXIER, Pascal, Limoges, Pulim, 2004. De façon plus générale, Fortunat défend la collaboration du souverain et des évêques pour la protection du peuple (REYDELLET, M., La royauté dans la littérature latine de Sidoine Apollinaire à Isidore de Séville Rome, École française de Rome, 1981, p. 297-344). Il s'agit plutôt de montrer la puissance thaumaturgique du saint qui, à travers l'intermédiaire animal, peut " corriger la décision du roi ", ce qui suggère une hiérarchie dans les autorités.

132. Entendons, comme s'il était une statue.

133. per ipsum iter : confusion habituelle dans le latin tardif de ipse et idem. 
ce cadavre sorti de sa sépulture était déjà enseveli dans le marbre et les chevaux ne pouvaient faire un pas, comme si de la poussière de ce corps étaient sorties des chaînes, jusqu'à ce qu'en arrivant l'évêque libérât par la prière ceux que son silence a [jusque-là] cloués au sol.

43. Il ne faut pas moins faire connaître encore un miracle. Comme au monastère de Tintilliacense, le moine Gennomer était privé de la lumière des yeux et que de longues années s'étaient écoulées [pour lui] dans une seule nuit de cécité, il demanda au très saint homme de faire sur lui le signe de la croix. Après quoi, la splendeur vivifiante de la lumière pénétra ses yeux, chassa les ténèbres et le soleil [qui lui était] étranger resplendit pour lui.

44. Il y a encore parmi bien d'autres choses cet exemple vénérable. Comme dans la cité d'Angers une tour accolée à la porte ${ }^{134}$ avait été transformée en prison pour les condamnés, le bienheureux Aubin passant par là fut surpris par les cris des prisonniers. Alors, suppliant, il se rendit auprès du juge ${ }^{135}$ pour que par pitié il les relâchât de la prison ${ }^{136}$.

45. Comme celui-ci faisait la sourde oreille, bientôt le pontife se tournant vers Dieu en une quête confiante, pria le ciel avec tant d'intimité dans sa voix que là où le saint épancha sa prière, un bloc de pierre d'une taille étonnante se détacha et ouvrit l'accès de la porte aux prisonniers parce que, face à sa prière, la pierre ne put conserver sa solidité.

46. Sortis vivants de là comme d'un tombeau, rendant grâce au seigneur Aubin dans la basilique de saint Maurille ${ }^{137}$, ils se jetèrent à ses pieds parce qu'il avait fait revenir les suspects de la mort au salut.

47. De même, lorsqu'une femme saisie par l'esprit malin se présenta au bienheureux Aubin, criant et se lamentant, voilà que l'Ennemi se fixa sur son œil sous l'aspect d'une poche de sang.

48. Alors le pontife faisant le signe de la croix l'apostropha en ces termes : «Ennemi, que l'œil que tu n'as pas donné, tu ne puisses l'enle-

134. Une enceinte fortifiée (castrum), attestée dans la deuxième moitié du v $\mathrm{v}^{\mathrm{e}}$ siècle, avait été construite au nord-ouest de la civitas sur un éperon rocheux naturel. L'existence de quatre tours et de quatre portes situées aux quatre points cardinaux est confirmée par l'archéologie (Topographie chrétienne des cités de la Gaule des origines au milieu du VIII siècle, t. V : Province ecclésiastique de Tours [Lugdunensis tertia], par PIETRI, Luce et BiARne, Jacques, Paris, 1987, p. 72).

135. Le judex est l'équivalent du comes.

136. La libération miraculeuse des prisonniers est fréquente dans les vies de saints, en particulier chez Fortunat. Saint Aubin n'intervient pas ici en tant que defensor civitatis, mais en tant qu'évêque chargé par Dieu d'une mission charitable : il suit les formes juridiques, s'adresse d'abord au juge / comte avant de déclencher la procédure céleste du miracle. On trouve un miracle comparable dans la Vita Germani, c. 66, éd. cit. [supra, n. 2], p. 412 : les prisonniers libérés miraculeusement de la tour-prison de Paris " se précipitent à l'église ".

137. Il s'agit de la basilique funéraire de l'évêque, située à l'extérieur des remparts romains. Elle a disparu en 1791 (PIÉTRI / BIARNE Topographie chrétienne des cités de la Gaule [supra, n. 134], t. V, p. 75-76). Sur l'histoire de l'abbaye Saint-Aubin, voir l'Introduction des Miracles post mortem. 
ver ". Bientôt un filet de sang s'ouvrit un passage et sortit de l'abcès sous forme de phlébotomie; après cette saignée, l'immonde Ennemi disparut sans blesser l'œil et la jeune fille s'en tira saine et sauve par la force du signe de la croix.

49. Mais il faut maintenant exposer cet utile exemple de sa grandeur d'âme. Quand il s'agissait du service de Dieu, il n'avait aucun égard pour la personne des rois et des puissants ${ }^{138}$. Enfin, pour atteindre le comble de la grâce céleste, condamnant à bon droit les copulations exécrables de noces incestueuses ${ }^{139}$, il imitait saint Jean d'une manière irréprochable ${ }^{140}$.

50. Mais tout ce qu'il aura souffert de ce fait personne ne pourra l'exposer convenablement : en vérité, il aurait souhaité devenir martyr; il ne lui manqua que la droite de l'assassin, mais, sans aucun doute, il mérita la palme du martyre, lui qui ne se cacha pas d'avoir formulé ce vœu.

51. Outre ses autres tâches, se rendant à la convocation des synodes réunis assez souvent pour cette cause ${ }^{141}$ et, à la fin, sur l'injonction de très nombreux évêques, il fut contraint de force par ses frères d'absoudre les personnes qu'il avait excommuniées ${ }^{142}$.

52. Et comme on lui demandait d'apposer aussi lui-même le signe de la croix sur les eulogies ${ }^{143}$ que les autres évêques avaient bénies pour les envoyer à une personne excommuniée, il répondit à l'assemblée épiscopale : " Même si moi, sur votre ordre, je suis forcé d'apposer le signe de la croix, puisque vous refusez la cause de Dieu, c'est Dieu Lui-même qui est en puissance de se venger ${ }^{144}$."

53. Après quoi, avant que la personne excommuniée ne porte les eulogies à sa bouche, elle expira et avant que le porteur [de pain] ne parvînt à destination, c'est la parole de l'évêque qui prévalut : il se rendit même auprès de bienheureux Césaire, évêque d'Arles, pour le consulter sur ce sujet $^{145}$.

138. Voir Paulini, Vita Ambrosii, 47, 18-20, in Vita di Ambrogio, vita di Agostino, introduzione di Mohrmann Chr., testo critico e commentato di BASTIAENSEN A. R., Milan, 1989, p. 114.

139. Voir infra, c. 51-52 et Introduction, supra.

140. Allusion à la parole de Jean-Baptiste ("Il ne t'est pas permis de l'avoir [Hérodiade] ", Mt 14, 3).

141. Sur la participation de saint Aubin aux synodes d'Orléans de 538 et 540, voir Introduction, supra.

142. Voir supra.

143. Le contexte de l'excommunication pourrait laisser supposer que les eulogies désignent ici le pain et le vin consacrés, mais, comme nous l'a fait remarquer Marc Reydellet, le mot désigne toujours des cadeaux - gâteaux ou parcelles de pains que les fidèles offraient pour les faire bénir. Fortunat précise bien que ces eulogies étaient bénies par les autres évêques. Ajoutons qu'à cette époque il est exclu que les hosties et le calice soient consacrés par plus d'une personne.

144. Aubin se soumet à l'autorité du concile mais, comme un prophète vétéro-testamentaire, il en appelle directement à la vengeance divine.

145. Les relations entre Aubin et Césaire ont donné lieu à diverses supputations. Aubin se serait rendu auprès de Césaire avant la mort de l'évêque d'Arles en 543. Il aurait été 
54. Mais parce que nous ne pouvons dérouler chacun de ses très nombreux actes, qu'il suffise d'en avoir évoqué un petit nombre. Nous croyons ainsi qu'il est avant tout nécessaire de présenter le témoignage du bienheureux Aubin vivant après sa mort, car, bien que son corps soit enfermé dans la tombe, cependant l'âme de ce juste a produit en récompense une grande abondance de fruits.

55 . Donc ${ }^{146}$, comme saint Germain, évêque ${ }^{147}$, les évêques de la province $^{148}$, le pontife qui lui avait succédé et le peuple voulaient transporter avec dévotion les membres du saint dans une nouvelle basilique ${ }^{149}$ et qu'en raison de l'étroitesse du caveau ${ }^{150}$ où il avait été placé, il était impossible d'en extraire le corps sacré, que tous étaient dans l'embarras et ne savaient que faire, la puissance ${ }^{151}$ du très saint homme vient au secours de l'inquiétude du peuple.

56. En effet, comme tous attendaient indécis, soudain, sur un signe divin, le mur du caveau qui était à ses pieds s'étant brisé, trois pierres se détachèrent de la partie orientale : c'était là le signe montrant par quel endroit il voulait qu'on le fît sortir.

57. Cependant, après qu'on eut ménagé un accès, tandis que le concert des chanteurs de psaumes s'avance vers le saint tombeau, à l'endroit par

rejoint à Arles par saint Lubin (Vies des saints et des bienheureux, t. IX, Paris, 1950, p. 304). Dom François Chamard, avec l'imagination romantique et l'absence d'esprit critique qui le caractérisent, fait appel à la vie de sainte Maure, vierge et martyre. Cette jeune fille d'une incroyable beauté, appartenait à une famille d'Écosse. Au retour d'un voyage à Rome, elle aurait rencontré Césaire à Arles et ce dernier l'aurait renvoyée à saint Aubin, à Angers où Maure fit un miracle éclatant (CHAMARD, Les vies des saints personnages d'Anjou [supra, n. 6], ici p. 215-216). Sur le prestige de Césaire d'Arles en Gaule, voir Introduction [supra, n. 47].

146. Comme les chapitres 11 et 26, l'épilogue est introduit par Igitur.

147. Il s'agit de saint Germain, évêque de Paris († 576). On date ce voyage du dies natalis du saint, le $1^{\mathrm{er}}$ mars, d'une année qui pourrait être 568 : Germain, qui avait participé au concile de Tours de novembre 567, aurait profité de l'occasion pour se rendre à Angers avec les évêques comprovinciaux. Il reste que la durée du séjour de Germain de Paris dans la cité de saint Martin a de quoi étonner. La présence même de Germain à Angers est surprenante, et plus encore le silence fait par Fortunat sur le métropolitain de Tours Eufronius et le nom du successeur d'Aubin : s'agissait-il d'Eutrope, dont Mgr Duchesne a contesté l'existence avec des arguments solides (Fastes épiscopaux de l'ancienne Gaule [supra, n. 99], t. II, p. 349 sqq.) ou de Domitien? Voir la discussion de cette affaire dans FAUQUIER, La sainteté à la fin de l'Antiquité [supra, n. 22], p. 368, n. 5.

148. Aux v $\mathrm{v}^{\mathrm{e}}$ et $\mathrm{vl}^{\mathrm{e}}$ siècles, la province de Tours comprenait la métropole de Tours, les évêchés du Mans, d'Angers, de Nantes, Rennes, Vannes (Coriosolites, Osismes, Province ecclésiastique de Tours [Lugdunensis tertia] par PIETRI et BIARNE [supra, n. 134], p. 15).

149. Voir infra, Introduction aux miracles post mortem de saint Aubin.

150. FAUQUIER, La sainteté à la fin de l'Antiquité [supra, n. 22], p. 368, n. 5 croit pouvoir risquer l'hypothèse que la cellula était une sorte de " réduit " très étroit où la dépouille de saint Aubin avait été si peu honorablement placée qu'il a été fort difficile de l'en extraire.

151. C'est ici le mot " puissance " qui rend le mieux virtus. Sur les différents sens de virtus, voir AXTERS, é., "Over "virtus" en heiligheids complex onder de Merowingers", Mélanges offerts au chanoine Albert de Mayer. Recueil de travaux d'histoire et de philologie, $3^{\mathrm{e}}$ série, fasc. 22-23, Louvain, 1946, p. 266-285. 
lequel on l'avait fait sortir, trois paralytiques, privés d'espoir depuis longtemps déjà, furent publiquement guéris et leurs nerfs déjà morts réapprirent à vivre par les mérites du cadavre, et, aussitôt, deux aveugles, pareillement rendus à la lumière, reçurent enfin la clarté du jour de l'ombre du défunt, reconnaissant assurément qu'ils pouvaient atteindre la lumière avec l'aide de celui dont la puissance avait pu faire une ouverture dans un mur.

58. Par ces miracles et les nombreux autres qui ont suivi, même si les membres de l'évêque reposent au tombeau, cependant par la grâce du Créateur les mérites du confesseur vivent pour toujours.

59. C'est pourquoi, orné par un don céleste de fleurs vénérables, il occupa les hauteurs de l'épiscopat pendant vingt ans et six mois, exerçant son gouvernement selon les règles, et la quatre-vingtième année de sa vie, accomplissant avec bonheur parmi les puissances ${ }^{152}$ au comble de la béatitude cette parole prophétique ${ }^{153}$, il rendit aux cieux le jour des calendes de mars ${ }^{154}$, au milieu au milieu des applaudissements des anges, son âme très chère à Dieu arrachée au siècle, pour demeurer avec le Christ, par Notre Seigneur Jésus-Christ, à qui appartiennent l'honneur et la puissance dans les siècles des siècles. Amen.

152. Sur les conseils de Marc Reydellet, nous avons corrigé le barbarisme de Bruno Krusch potestatibus en potentatibus. Il s'agit sans doute des Puissances angéliques dont il est question juste après (voir I P, 3, 22).

153. Peut-être allusion à Ps 20 (19) : "Maintenant je connais que Yahvé donnera le salut à son messie. Des cieux de sainteté il lui répond par les gestes sauveurs de sa droite. "

154. Aubin est mort le $1^{\mathrm{er}}$ mars 550 . Il avait été élu abbé vers 35 ans (c. 21). Il gouverna la communauté 25 ans (c. 23). Il est donc bien mort " dans la quatre-vingtième année de sa vie ", comme le dit Fortunat, après vingt ans et six mois d'épiscopat. 


\section{RÉSUMÉ}

Installé à Poitiers, Venance Fortunat a contribué à créer le culte de saint Aubin, évêque d'Angers de 538 à 550. La Vita s. Albini (BHL 234) répond à une commande de l'évêque d'Angers Domitianus, mort entre 569 et 572. Nous en publions ici une traduction fondée sur l'édition de Bruno Krusch en 1885 (MGH, AA, IV 2, p. 27-33). Même s'il contient quelques précisions historiques, le récit obéit aux mêmes conventions que les autres vitae en prose de Venance Fortunat : naissance noble du saint, imitation du Christ dans la vie monastique et ascétique permettant au saint d'accéder à la " vertu " thaumaturgique. Ce sont les miracles qui occupent l'essentiel de la dernière partie, consacrée à l'épiscopat d'Aubin.

Du point de vue formel, la Vita recourt au style relevé dans le discours dédicataire; la suite du texte, composée d'un enchaînement de brefs épisodes, cache, sous une apparence " rustique " (sermo rusticus), les éclats d'une rhétorique subtile.

\section{ABSTRACT}

Settled in Poitiers, Venentius Fortunatus contributed to create the cult of St Aubin, bishop of Angers (538-550). His Vita s. Albini (BHL 234) was commissioned before 569-572 by Domitianus, bishop of Angers. The translation published here is founded on Bruno Krusch's edition in 1885 (MGH, AA, IV 2, p. 27-33). If the Vita contains some historical elements, however the narrative follows the model of Venantius Fortunatus's other prose works: the saint's noble birth, the imitation of Christ in his monastic and ascetic life, allowing him to obtain a thaumaturgic power. In the last part of the Vita, concerning Aubin's episcopate, miracles are particularly frequent.

The style of the Vita's dedication is sophisticated and the narrative is composed of a sequence of short episodes, written in an erudite but apparently rustic style (sermo rusticus). 